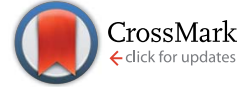

Cite this: Chem. Sci., 2015, 6, 4623

\title{
Luminescent zinc(II) and copper(I) complexes for high-performance solution-processed monochromic and white organic light-emitting devices $\uparrow$
}

\author{
Gang Cheng, ${ }^{\text {abd }}$ Gary Kwok-Ming So, ${ }^{a}$ Wai-Pong To, ${ }^{a}$ Yong Chen, ${ }^{c}$

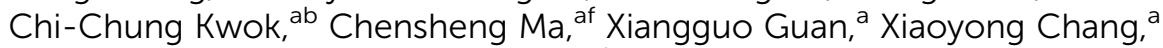 \\ Wai-Ming Kwok ${ }^{e}$ and Chi-Ming Che ${ }^{* a b}$
}

\begin{abstract}
The synthesis and spectroscopic properties of luminescent tetranuclear zinc(II) complexes of substituted 7azaindoles and a series of luminescent copper(I) complexes containing 7,8-bis(diphenylphosphino)-7,8dicarba-nido-undecaborate ligand are described. These complexes are stable towards air and moisture. Thin film samples of the luminescent copper(1) complexes in 2,6-dicarbazolo-1,5-pyridine and zinc(II) complexes in poly(methyl methacrylate) showed emission quantum yields of up to 0.60 (for $\mathrm{Cu}-3$ ) and 0.96 (for Zn-1), respectively. Their photophysical properties were examined by ultrafast time-resolved emission spectroscopy, temperature dependent emission lifetime measurements and density functional theory calculations. Monochromic blue and orange solution-processed OLEDs with these $\mathrm{Zn}(\mathrm{II})$ and $\mathrm{Cu}(\mathrm{I})$ complexes as light-emitting dopants have been fabricated, respectively. Maximum external quantum efficiency (EQE) of $5.55 \%$ and Commission Internationale de l'Eclairage (CIE) coordinates of $(0.16,0.19)$ were accomplished with the optimized Zn-1-OLED while these values were, respectively $15.64 \%$ and $(0.48,0.51)$ for the optimized Cu-3-OLED. Solution-processed white OLEDs having maximum EQE of $6.88 \%, \mathrm{CIE}$ coordinates of $(0.42,0.44)$, and colour rendering index of 81 were fabricated by using these luminescent $\mathrm{Zn}(॥)$ and $\mathrm{Cu}(\mathrm{I})$ complexes as blue and orange light-emitting dopant materials, respectively.
\end{abstract}

Received 15th October 2014 Accepted 15th May 2015

DOI: $10.1039 / \mathrm{c} 4 \mathrm{sc} 03161 \mathrm{j}$

www.rsc.org/chemicalscience

\section{Introduction}

Organic light-emitting diodes (OLEDs), particularly the solution processed ones, are appealing new technology for display and lighting purposes. ${ }^{1-4}$ For high performance OLEDs, phosphorescent dopant materials based on complexes of platinum group metals such as iridium(III), platinum(II), osmium(II) and

${ }^{a}$ State Key Laboratory of Synthetic Chemistry, HKU-CAS Joint Laboratory on New Materials, and Department of Chemistry, The University of Hong Kong, Pokfulam Road, Hong Kong SAR, China. E-mail: cmche@hku.hk

${ }^{b} H K U$ Shenzhen Institute of Research and Innovation, Shenzhen 518053, China

'Key Laboratory of Photochemical Conversion and Optoelectronic Materials, Technical Institute of Physics and Chemistry, Chinese Academy of Sciences, Beijing 100190, China

${ }^{d}$ State Key Laboratory on Integrated Optoelectronics, College of Electronic Science and Engineering, Jilin University, Changchun 130012, China

${ }^{e}$ Department of Applied Biology and Chemical Technology, The Hong Kong Polytechnic University, Hung Hom, Kowloon, Hong Kong SAR, China

${ }^{f}$ School of Chemistry and Chemical Engineering, Shenzhen University, Shenzhen 518060, China

$\dagger$ Electronic supplementary information (ESI) available: Experimental procedures, device performances, and computational details. CCDC 1054456, 1400003 and 1400004. For ESI and crystallographic data in CIF or other electronic format see DOI: $10.1039 / \mathrm{c} 4 \mathrm{sc} 03161 \mathrm{j}$
gold(III) are commonly used, some of which have already demonstrated industrial applications..$^{5-8}$ On the other hand, the applications of luminescent complexes of earth abundant metals such as that of copper(I) and zinc(II) described in this work in OLED science and technology are relatively sparse. In the literature, the applications of luminescent $\mathrm{Zn}$ (II) complexes in materials science are well documented. As examples, $\mathrm{Zn}(\mathrm{II})-2-$ (2-hydroxyphenyl)benzothiazolates have been used as whitelight emitting, blue-light emitting, electron transporter, and/or host materials in OLEDs. ${ }^{9,10 a-g}$ However, electroluminescent (EL) efficiencies of white ${ }^{10 d}$ and blue ${ }^{9 d}$ OLEDs with most reported luminescent $\mathrm{Zn}$ (II) complexes are not high with maximum current efficiencies (CEs) of 1.39 and $0.54 \mathrm{~cd} \mathrm{~A}^{-1}$, respectively. In recent work, by using the principle of thermally activated delayed fluorescence (TADF), Adachi and co-workers reported high performance green OLEDs with luminescent $\mathrm{Zn}$ (II) complexes. ${ }^{10 h}$ Besides Zn(II) complexes, there has been a spurred interest to develop luminescent $\mathrm{Cu}(\mathrm{I})$ materials for OLEDs. With luminescent $\mathrm{Cu}(\mathrm{I})$ dopant material, high performance OLEDs with $\mathrm{EQE}$ of up to $21.3 \%$ have been reported in the literature. $^{11-13}$ Nonetheless, the reported luminescent $\mathrm{Cu}(\mathrm{I})$ complexes that gave high EQEs in OLEDs show green emission and/or not stable towards air and moisture. ${ }^{12 b, 13 c} \mathrm{~A}$ charged $\mathrm{Cu}(\mathrm{I})$ 
complex had been reported as light-emitting material in solution-processed OLED with EQE of up to $15.0 \% .{ }^{13 c}$ In the present work, we report the spectroscopic and photophysical properties of a panel of high efficiency, blue fluorescent $\mathrm{Zn}$ (II) complexes Zn-1, Zn-2 and Zn-3 and a series of air-stable, charge-neutral luminescent $\mathrm{Cu}(\mathrm{I})$ complexes containing 7,8-bis(diphenylphosphino)-7,8-dicarba-nido-undecaborate ligand (Scheme 1). The emissions of $\mathbf{C u}-\mathbf{2}, \mathbf{C u}-\mathbf{3}$ and $\mathbf{C u}-5$ have been confirmed to be TADF by nanosecond time-resolved emission spectroscopy, temperature dependent emission lifetime measurements and density functional theory (DFT) calculations. Solution-processed monochromic OLEDs with these luminescent $\mathrm{Zn}$ (II) and $\mathrm{Cu}(\mathrm{I})$ complexes have been fabricated and characterized. With Zn-1, Zn-2 and Zn-3 as blue emitters for solution-processed OLEDs, high CE of up to $8.12 \mathrm{~cd} \mathrm{~A}^{-1}$, corresponding EQE of $5.55 \%$, and Commission Internationale de l'Eclairage (CIE) coordinates of $(0.16,0.19)$ have been achieved with $\mathbf{Z n - 1}$ as emitter. For orange Cu-2 OLED, the EQE was up to $16.57 \%$. Finally, by combining the blue-light emitting Zn(II) complex Zn$\mathbf{1}$ and the orange $\mathrm{Cu}(\mathrm{I})$ complex $\mathbf{C u}-\mathbf{3}$, we have demonstrated a white solution-processed OLED with maximum EQE of $6.88 \%$, CIE coordinates of $(0.42,0.44)$ and colour rendering index of 81 . To our best knowledge, this is the first example of high performance white solution-processed OLED fabricated solely with metal emitters of non-platinum group metals.

\section{Results and discussion}

Chemical structures of $\mathbf{Z n - 1 - Z n - 3}$ and $\mathbf{C u - 1 - C u - 5}$ are depicted in Scheme 1. Details of their synthesis and characterization data are given in the ESI. $\dagger$ The $\mathrm{Zn}$ (II) complexes were prepared by refluxing 4-substituted- $1 H$-pyrrolo[2,3- $b]$ pyridines with triethylamine in methanol, followed by the addition of a methanolic solution of zinc(II) salt. The crude product was a white/yellow solid. It was purified by dissolving it in $\mathrm{CH}_{2} \mathrm{Cl}_{2}$ which was filtered through Celite and pre-concentrated. A white/yellow

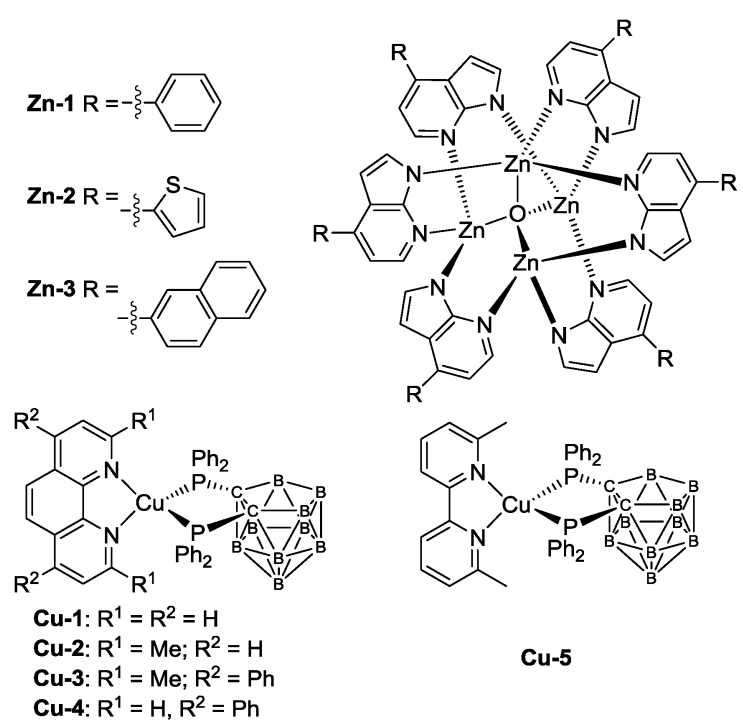

Scheme 1 Structures of $\mathrm{Zn}-1-\mathrm{Zn}-3$ and $\mathrm{Cu}-1-\mathrm{Cu}-5$. solid was obtained by precipitation with methanol followed by centrifugation and dried under vacuum. Attempts to grow crystals of Zn-1-Zn-3 with suitable quality for single-crystal $\mathrm{X}$-ray diffraction analysis were not successful. In view of the resemblance of the coordination mode of substituted 7-azaindolate with the parent 7-azaindolate, it is reasonable to propose an isostructural relationship among the $\mathrm{Zn}_{4} \mathrm{O}(\mathrm{AID})_{6}$ and $\mathbf{Z n - 1 -}$ Zn-3 complexes. A previous study had disclosed the crystal structure of $\mathrm{Zn}_{4} \mathrm{O}(\mathrm{AID})_{6}{ }^{{ }^{\boldsymbol{g}}}{ }^{\boldsymbol{b}}$ To cautiously confirm the reported structural description, as depicted in Fig. S60 (ESI†), we reexamined the crystal structure of $\mathrm{Zn}_{4} \mathrm{O}(\mathrm{AID})_{6}$ which was prepared following the same synthetic procedure as Zn-1-Zn-3. Crystals of $\mathrm{Zn}_{4} \mathrm{O}(\mathrm{AID})_{6}$ with quality suitable for structure determination by X-ray diffraction analysis were obtained by slow diffusion of diethyl ether into a $\mathrm{CH}_{2} \mathrm{Cl}_{2}$ solution of $\mathrm{Zn}_{4}$ $\mathrm{O}(\mathrm{AID})_{6}$. The $\left[\mathrm{Zn}_{4} \mathrm{O}\right]$ core has a central oxygen atom surrounded by four $\mathrm{Zn}$ atoms in tetrahedral geometry. Each 7-azaindolate ion serves as a bridging ligand connecting two $\mathrm{Zn}$ (II) ions via coordination to the nitrogen atoms of the pyrrole and pyridine moieties, respectively. The current structural solution (CCDC deposition number 1054456) provides a more chemically rational model than the previously reported one. In the previously reported structure, the lattice solvent molecules were modelled as disordered $\mathrm{CH}_{2} \mathrm{Cl}_{2}$ and water. In this work, a disordered diethyl ether was found to be more sensible. Although crystals of $\mathbf{Z n - 1 - Z n - 3}$ with quality suitable for single crystal X-ray diffraction analysis have not been obtained, the $\mathrm{Zn}_{4} \mathrm{O}(\mathrm{L})_{6}(\mathrm{~L}=$ substituted 7-azaindolate ligand) core structures of $\mathbf{Z n - 1 - Z n - 3}$ could be inferred by mass spectrometry and NMR experiments. The ${ }^{13} \mathrm{C}$ NMR and ${ }^{1} \mathrm{H}^{-13} \mathrm{C}$ HSQC NMR spectra of Zn-1-Zn-3 show multiplet signals corresponding to the seven carbon atoms of the 7-azaindole core of each 4-substituted- $1 \mathrm{H}$ pyrrolo[2,3- $b]$ pyridine at $\delta \sim 100, \sim 112, \sim 123, \sim 138, \sim 143$ and $\sim 156$ ppm, respectively, and three of these multiplet signals could be assigned to three quaternary carbons on the 7-azaindole core. The multiplet signals between $\delta \sim 126$ and $\sim 137 \mathrm{ppm}$ correspond to the carbon atoms of the 4-substitution of the 4substituted-1 $H$-pyrrolo[2,3- $b]$ pyridine ligand. Complexes Zn-1Zn-3 are thermally stable with high decomposition temperature $\left(T_{\mathrm{d}}\right.$ corresponds to $5 \%$ weight loss in thermogravimetric analysis (TGA) measurement) of $369-440{ }^{\circ} \mathrm{C}$ (Fig. S1 in ESI $\dagger$ ).

The $\mathrm{Cu}(\mathrm{I})$ complexes were prepared by reacting $\left[\mathrm{Cu}(\mathrm{MeCN})_{4}\right]$ $\mathrm{PF}_{6}$ with tetramethylammonium 7,8-bis(diphenylphosphino)7,8-dicarba-nido-undecaborate $\left(\left[\mathrm{NMe}_{4}\right]\left[\left(\mathrm{PPh}_{2}\right)_{2} \mathrm{C}_{2} \mathrm{~B}_{9} \mathrm{H}_{10}\right]\right)$ in ethanol followed by addition of phenanthroline or bipyridine ligand. ${ }^{\mathbf{1 4}}$ The crude product appeared as a yellow/orange solid and was purified by column chromatography on silica gel column with $\mathrm{CH}_{2} \mathrm{Cl}_{2}$ as eluent. Both ${ }^{1} \mathrm{H}$ NMR spectra of $\mathbf{C u 1}$ and Cu4 show doublet signals at $\sim 6.4$ and $\sim 9.9 \mathrm{ppm}$ that can be assigned to the protons at 2- and 9-position of the phenanthroline ligand. X-Ray crystal structures of $\mathbf{C u - 1}$ and $\mathbf{C u - 3}$ are determined in this work (Fig. S61 in ESI $\dagger$ and 1) while that of Cu-2 and Cu-4 have been reported. ${ }^{\mathbf{1 4}}$ The crystals of Cu-1 and Cu-3 were obtained by diffusing diethyl ether into $\mathrm{CH}_{2} \mathrm{Cl}_{2}$ solutions of the corresponding copper complex. The crystal structure of Cu-3 is shown in Fig. 1. Cu-3 adopts a distorted tetrahedral geometry with $\mathrm{N}-\mathrm{Cu}-\mathrm{N}$ and $\mathrm{P}-\mathrm{Cu}-\mathrm{P}$ angles of 80.85 
and $91.47^{\circ}$, respectively. The lengths of $\mathrm{N}-\mathrm{Cu}$ and $\mathrm{P}-\mathrm{Cu}$ bonds are 2.074-2.078 and 2.249-2.264 $\AA$, respectively, similar to those found in $\mathrm{Cu}(\mathrm{I})$ complexes bearing diimine and diphosphine ligands. ${ }^{11 e, 14}$

\section{Photophysical properties and TRE measurements}

Photophysical properties of Zn-1-Zn-3 in solutions, thin film, and the solid state are summarized in Table 1. Complexes Zn-1Zn-3 show an intense absorption band at 299-308 $\mathrm{nm}(\varepsilon=4.3-$ $\left.6.4 \times 10^{4} \mathrm{dm}^{3} \mathrm{~mol}^{-1} \mathrm{~cm}^{-1}\right)$ and a broad shoulder at 350-368 $\mathrm{nm}\left(\varepsilon=2.6-3.8 \times 10^{4} \mathrm{dm}^{3} \mathrm{~mol}^{-1} \mathrm{~cm}^{-1}\right)$ in $\mathrm{CH}_{2} \mathrm{Cl}_{2}$ as depicted in Fig. 2a. The band at $299-308 \mathrm{~nm}$ is similarly present in the free ligand but not in $\left[\mathrm{Zn}_{4} \mathrm{O}\left(\mathrm{O}_{2} \mathrm{CMe}\right)_{6}\right]{ }^{9 \boldsymbol{b}}$ hence is assigned to intraligand (IL) ${ }^{1} \pi \rightarrow \pi^{*}$ transition. The shoulder at $350-368$ $\mathrm{nm}$ is attributed to a metal perturbed $\mathrm{IL}^{1} \pi \rightarrow \pi^{*}$ transition. No significant shift (5-11 nm) in absorption peak maxima is observed for $\mathbf{Z n - 1}$ in $\mathrm{MeCN}, \mathrm{CH}_{2} \mathrm{Cl}_{2}, \mathrm{DMF}$, THF and toluene (Fig. S2, ESI $\dagger$ ).

Emission spectra of $\mathbf{Z n - 1 - Z n - 3}$ with concentrations at $10^{-5} \mathrm{M}$ in degassed $\mathrm{CH}_{2} \mathrm{Cl}_{2}$ solutions are depicted in Fig. 2b. An intense emission with $\lambda_{\max }$ at 455-467 $\mathrm{nm}(\Phi=0.45-0.66 ; \tau=8-15 \mathrm{~ns})$ is observed upon excitation of the $\mathrm{Zn}$ (II) complexes at $\sim 350 \mathrm{~nm}$. No distinct variation in emission quantum yields of different batches of samples of the $\mathrm{Zn}$ (II) complexes from independent preparation was observed. Femtosecond time-resolved fluorescence (fs-TRF) measurements with excitation wavelength at 350 nm were undertaken. The TRF spectra and related fluorescence decay profiles of $\mathbf{Z n - 1 - Z n - 3}$ are shown in Fig. S10 (ESI†). Comparison of TRF and steady-state emission spectra recorded in the same solvent system revealed that TRF spectra of Zn-1-Zn-3 with decay lifetimes of 8-15 ns closely resemble the corresponding steady-state emission spectra. Steady-state emissions of $\mathbf{Z n - 1 - Z n - 3}$ are attributed to fluorescence from the lowest singlet excited state $\left(S_{1}\right)$. Photophysical properties of $\mathrm{Cu}(\mathrm{I})$ complexes $\mathbf{C u - 1 - C u - 5}$ are given in Table 1. Cu-1-Cu-5 show strong absorption bands at 271-305 $\mathrm{nm}\left(\varepsilon=2.0-4.3 \times 10^{4} \mathrm{dm}^{3}\right.$ $\left.\mathrm{mol}^{-1} \mathrm{~cm}^{-1}\right)$ and $438-473 \mathrm{~nm}\left(\varepsilon=0.3-0.69 \times 10^{4} \mathrm{dm}^{3} \mathrm{~mol}^{-1}\right.$ $\mathrm{cm}^{-1}$ ) in $\mathrm{CH}_{2} \mathrm{Cl}_{2}$ as depicted in Fig. S6. $\dagger$ The low energy absorption band of Cu-3 at $\lambda_{\max }=446 \mathrm{~nm}$ in DMF is red-shifted to $\lambda_{\max }=461 \mathrm{~nm}$ in the less polar solvent, benzene (Fig. S8a $\dagger$ ).

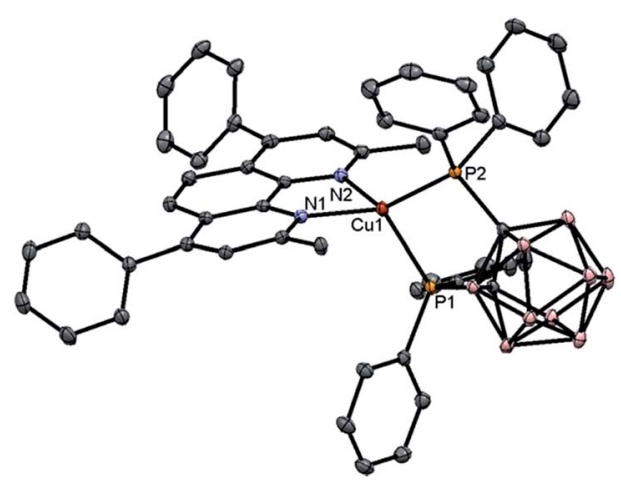

Fig. 1 X-Ray crystal structure of Cu-3. Hydrogen atoms and solvent molecules are omitted for clarity.
Complexes Cu-1-Cu-5 are non-emissive or weakly emissive with quantum yields of lower than 0.1 in dilute solutions. However, high emission quantum efficiency of up to 0.62 has been observed with Cu-3 in PYD2 thin film at room temperature and in 2-MeTHF glassy solution at $77 \mathrm{~K}$. The solid-state emission spectra of Cu-1-Cu-5 are depicted in Fig. S7.†

To examine the origin of the emission from these $\mathrm{Cu}(\mathrm{I})$ complexes, nanosecond TRE (ns-TRE) measurements on Cu-1, Cu-2 and $\mathbf{C u}-3$ in $\mathrm{CH}_{2} \mathrm{Cl}_{2}$ were performed. The results are, respectively, depicted in Fig. 3, 4 and S11. $\dagger$ An emission with $\lambda_{\max } \sim 690 \mathrm{~nm}$ is observed for $\mathbf{C u - 1}$. This emission is short-lived and decays rapidly in time scale faster than the time resolution of TRE measurement ( $\sim 2 \mathrm{~ns})$. Therefore, this emission is attributable to prompt fluorescence from the $S_{1}$ singlet excited state. Of note, there is a massive red-shift in energy $(\sim 7000$ $\mathrm{cm}^{-1}$ ) of the fluorescence from the absorption $\left(\lambda_{\max } \sim 465 \mathrm{~nm}\right)$ spectrum, suggesting large structural distortion of the emissive excited state from the ground state. ${ }^{15}$ The massive excited state structural distortion facilitates non-radiative decay, which may account for the weakly emissive nature of this complex in solutions at room temperature.

The emission $\lambda_{\max }$ of $\mathbf{C u - 2}$ and $\mathbf{C u - 3}$ (Fig. $4 \mathrm{a}$ and S11a $\dagger$ ) are at $\sim 620$ and $\sim 640 \mathrm{~nm}$, respectively. Unlike that of $\mathbf{C u}-\mathbf{1}$, these emissions decay in time scales of hundreds of nanoseconds to tens of microseconds. Analysis of the decay kinetics of emission intensity (measured by the integrated area of transient emission spectra) revealed a bi-exponential dynamics (Fig. $4 \mathrm{~b}$ and $\mathrm{S} 11 \mathrm{~b} \dagger$ ). The first decay component (Fig. 4c and S11c $\dagger$ ) has time constant faster than the time resolution of the TRE measurement and the second component (Fig. $4 \mathrm{~d}$ and S11d $\dagger$ ) has a lifetime of $\sim 152 \mathrm{~ns}$ and $\sim 210$ ns for $\mathbf{C u - 2}$ and $\mathbf{C u}-3$ in the open air condition, respectively. A decay lifetime of $\sim 1.27 \mu \mathrm{s}$ is observed for the emission of $\mathbf{C u}-\mathbf{3}$ in the deoxygenated condition by purging the sample solution with nitrogen. For $\mathbf{C u - 2}$ or $\mathbf{C u - 3}$, the timeresolved emission spectra recorded at different time intervals are similar. The first component, owing to its very fast decay time, can be attributed to prompt fluorescence from the $S_{1}$ singlet excited state; the second component with lifetime of hundreds of nanoseconds for $\mathbf{C u}-2$ and $\mathbf{C u}-3$ in air and $\sim 1.27 \mu \mathrm{s}$ for $\mathbf{C u - 3}$ in the deoxygenated condition is tentatively attributed to delayed fluorescence (DF) also from the $S_{1}$ state produced through thermally activated conversion from closely lying emissive triplet state. The much longer lifetime of DF under the deoxygenated condition is because the lifetime of DF is defined by the lifetime of the triplet state which is known to be much longer-lived in deoxygenated condition due to elimination of the oxygen quenching.

To support the delayed fluorescence assignment, emission lifetimes at various temperatures have been recorded for $\mathbf{C u}-\mathbf{2}$, Cu-3 and Cu-5; the results are shown in Fig. S13, $\dagger 5$ and S14, $\dagger$ respectively. With decreasing temperature, the decay time of Cu-3 steadily increases before $200 \mathrm{~K}$; there is a sharp increase in decay time at around $200 \mathrm{~K}$ to around $100 \mathrm{~K}$, and then the decay time remains relatively the same (Fig. 5). This finding could be accounted for by the drastic decrease of radiative decay rate $\left(k_{\mathrm{r}}\right)$ from $2.92 \times 10^{4} \mathrm{~s}^{-1}$ at $298 \mathrm{~K}$ to $3.92 \times 10^{2} \mathrm{~s}^{-1}$ at $77 \mathrm{~K}$. Similar finding was obtained for $\mathbf{C u - 2}$ and $\mathbf{C u - 5}$. The present emission 
Table 1 Photophysical data of $\mathrm{Zn}(॥)$ and $\mathrm{Cu}(\mathrm{I})$ complexes

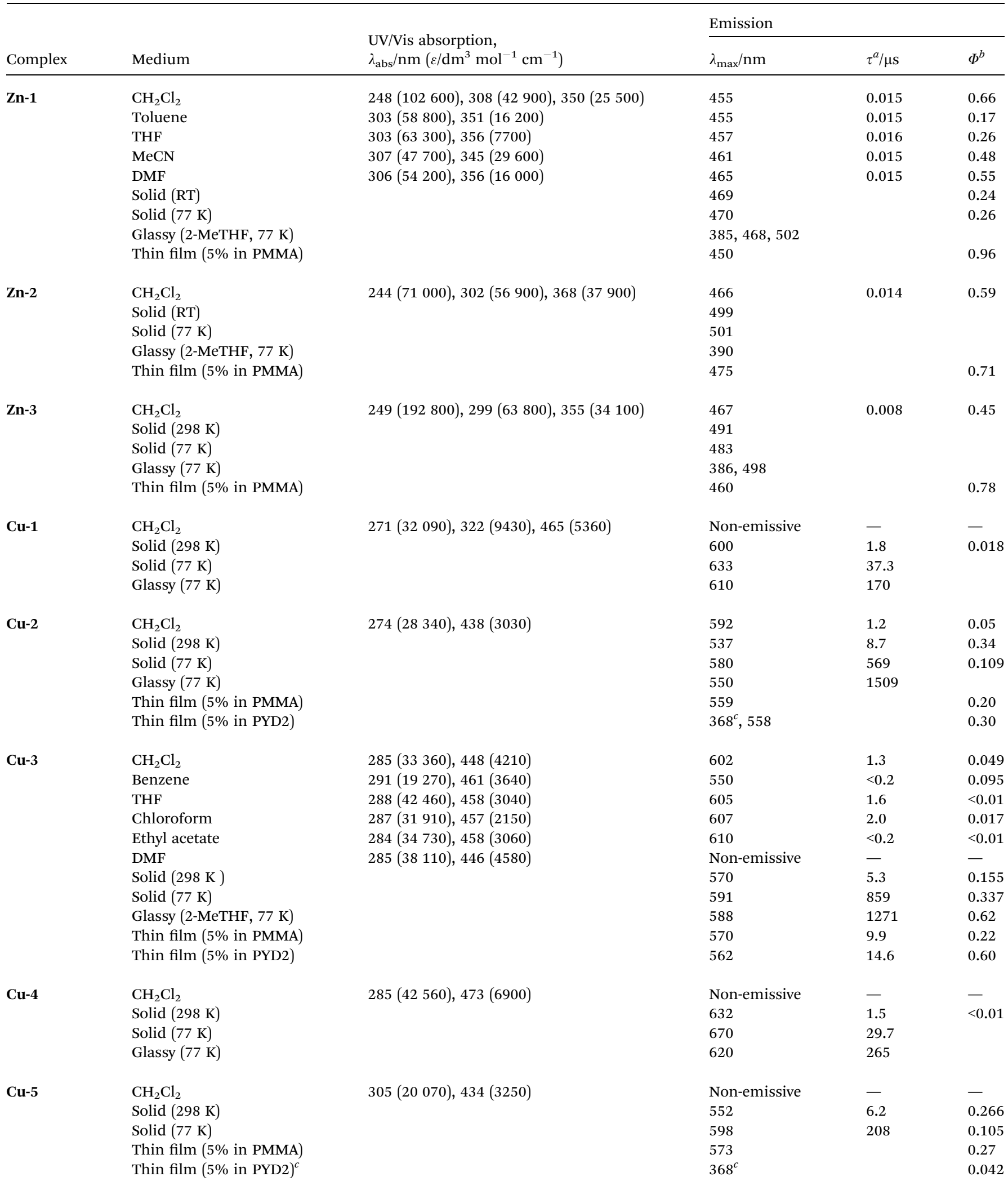

${ }^{a}$ Emission lifetime. ${ }^{b}$ Emission quantum efficiency; no distinct variation in emission quantum yields of different batch of samples of the Zn(II) complexes from independent preparation was observed. ${ }^{c}$ Incomplete energy transfer. 

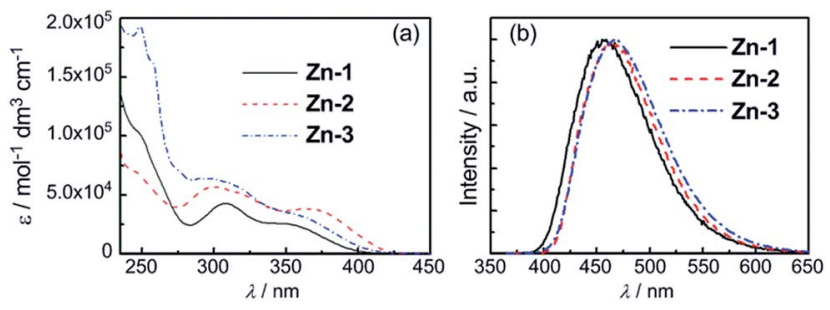

Fig. 2 (a) UV/Vis absorption spectra of $\mathrm{Zn}-1-\mathrm{Zn}-3$ in degassed $\mathrm{CH}_{2} \mathrm{Cl}_{2}$ $\left(1 \times 10^{-5} \mathrm{~mol} \mathrm{dm}^{-3}\right)$. (b) Emission spectra of $\mathbf{Z n - 1 - Z n - 3}$ in degassed $\mathrm{CH}_{2} \mathrm{Cl}_{2}\left(2 \times 10^{-5} \mathrm{~mol} \mathrm{dm}{ }^{-3}\right)$ at room temperature.

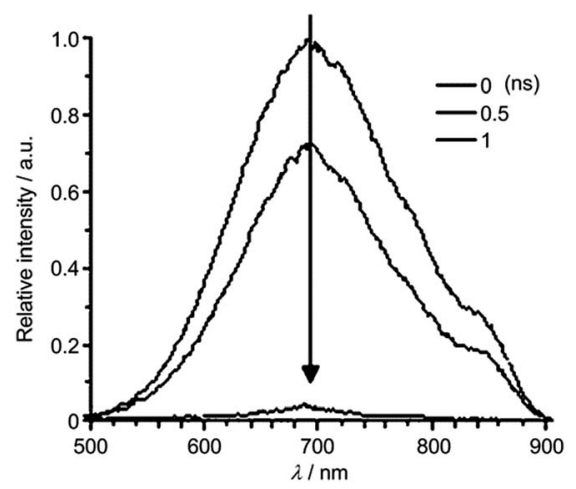

Fig. 3 ns-TRE of $\mathrm{Cu}-1$ in $\mathrm{CH}_{2} \mathrm{Cl}_{2}$ recorded at indicated time intervals after excitation at $350 \mathrm{~nm}$.

spectral and decay dynamics data are compatible with the mechanism proposed by Yersin and co-workers in that DF is formed due to thermally activated conversion from the triplet state lying close in energy to the $\mathrm{S}_{1}$ singlet. ${ }^{11 f}$ With reference to literature, the relationship between the change of emission decay time and temperature can be expressed as eqn (1): ${ }^{11 e}$

$$
\tau(T)=\frac{3+\exp \left[-\frac{\Delta E\left(\mathrm{~S}_{1}-\mathrm{T}_{1}\right)}{k_{\mathrm{B}} T}\right]}{\frac{3}{\tau\left(\mathrm{T}_{1}\right)}+\frac{1}{\tau\left(\mathrm{S}_{1}\right)} \exp \left[-\frac{\Delta E\left(\mathrm{~S}_{1}-\mathrm{T}_{1}\right)}{k_{\mathrm{B}} T}\right]}
$$

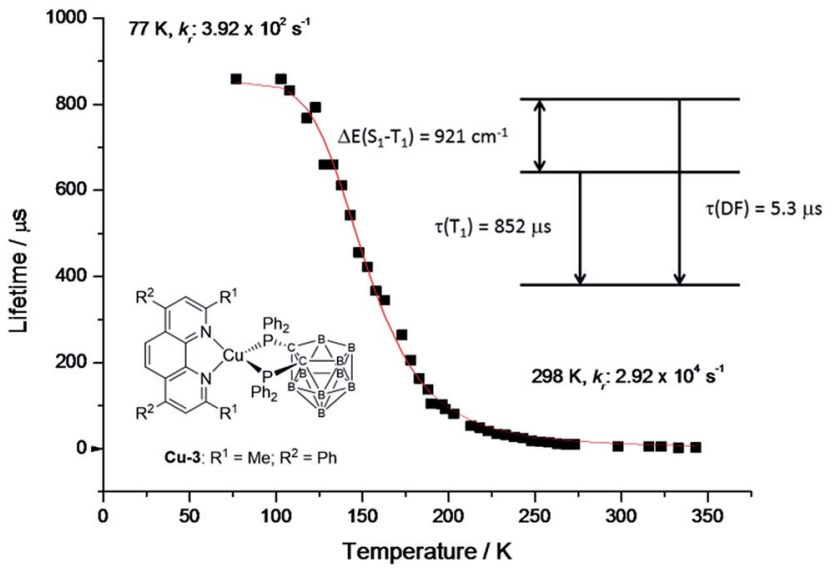

Fig. 5 Emission decay time of $\mathrm{Cu}-3$ powder vs. temperature. The red line represents a fit of eqn (1) to the experimental data with phosphorescence decay time $\tau\left(T_{1}\right)=852 \mu$ s measured at $77 \mathrm{~K}$. The resulting fit parameters are $\Delta E\left(\mathrm{~S}_{1}-\mathrm{T}_{1}\right)=921 \mathrm{~cm}^{-1}$ and $\tau\left(\mathrm{S}_{1}\right)=0.05 \mu \mathrm{s}$. The spontaneous fluorescence is not observed directly due to much faster intersystem crossing. $\tau(\mathrm{DF})=5.3 \mu \mathrm{s}$ is the decay time of the delayed fluorescence at ambient temperature.

By fitting the experimental data, $\Delta E\left(\mathrm{~S}_{1}-\mathrm{T}_{1}\right), \tau\left(\mathrm{S}_{1}\right)$ and $\tau\left(\mathrm{T}_{1}\right)$ of Cu-3 have been found to be $921 \mathrm{~cm}^{-1}, 0.04 \mu \mathrm{s}$ and $852 \mu \mathrm{s}$, respectively (the corresponding values for $\mathbf{C u}-\mathbf{2}$ and $\mathbf{C u}-\mathbf{5}$ are depicted in Fig. S13 and S14†).

\section{Electrochemical properties of $\mathrm{Zn}-1-\mathrm{Zn}-3$ and $\mathrm{Cu}-1-\mathrm{Cu}-5$}

Electrochemical properties of Zn-1-Zn-3 and $\mathbf{C u}-\mathbf{1}-\mathbf{C u}-\mathbf{5}$ were studied by cyclic voltammetry. For $\mathbf{Z n - 1}-\mathbf{Z n}-\mathbf{3}$, in the anodic scan, there is one irreversible wave at $0.87-0.89 \mathrm{~V} v s . \mathrm{FeCp}_{2}{ }^{0 /+}$. This wave is attributed to the ligand oxidation. No reduction peak is observed in the cathodic scan up to $-2.2 \mathrm{~V}$. The HOMO levels for Zn-1-Zn-3 were estimated to be -5.52 to $-5.56 \mathrm{eV}$ (Fig. S15-S17, ESI $\dagger$ ). All $\mathrm{Cu}(\mathrm{I})$ complexes show an irreversible reduction wave at -2.15 to $-2.48 \mathrm{~V} v s$. $\mathrm{FeCp}_{2}{ }^{\mathrm{O} /+}$ assigned to the reduction at phenanthroline/bipyridine ligand. For $\mathbf{C u}-\mathbf{1}$ and $\mathbf{C u}-\mathbf{4}$, they show three quasi-reversible/irreversible oxidation waves at 0.48-0.49, 0.74-0.77 and 1.14-1.17 V whereas Cu-2,
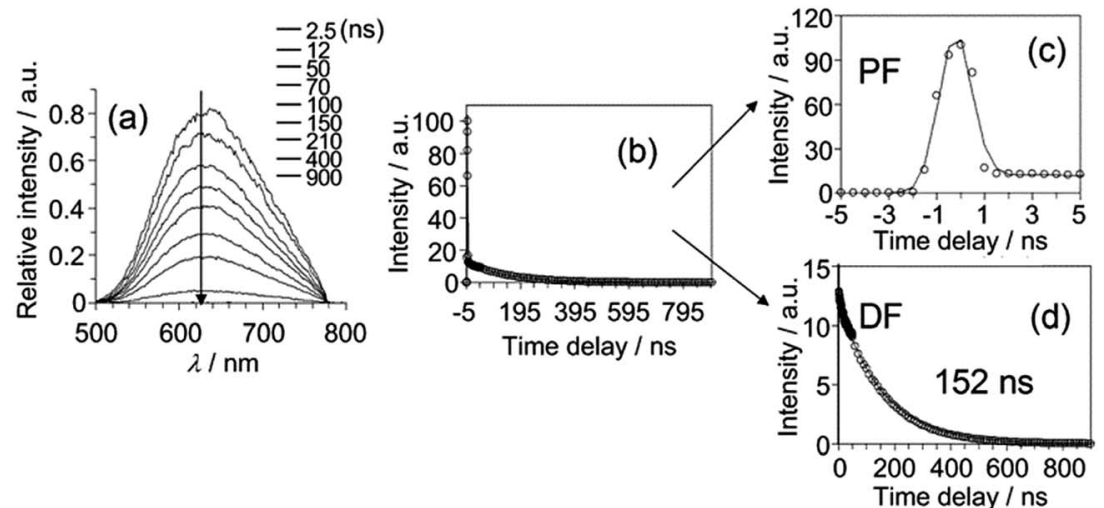

Fig. 4 (a) ns-TRE of $\mathrm{Cu}-2$ in $\mathrm{CH}_{2} \mathrm{Cl}_{2}$ recorded at indicated time intervals after excitation at $350 \mathrm{~nm}$. (b)-(d) ns-TRE decay profile of Cu-2 in $\mathrm{CH}_{2} \mathrm{Cl}_{2}$ recorded at $350 \mathrm{~nm}$. 
Cu-3 and Cu-5, which have methyl groups on the 2-, 9-position of phenanthroline/6-, 6'-position of bipyridine ligand, show two irreversible oxidation waves at 0.50-0.55 and 0.95-0.97 V vs. $\mathrm{FeCp}_{2}{ }^{\mathrm{O} /+}$. For all $\mathrm{Cu}(\mathrm{I})$ complexes, the first oxidation wave is assigned as oxidation of $\mathrm{Cu}(\mathrm{I})$ and the second to oxidation localized on the carborane ligand. The significantly different oxidation behaviour between $\mathrm{Cu}-1, \mathrm{Cu}-4$ and $\mathrm{Cu}-2, \mathrm{Cu}-3, \mathrm{Cu}-5$ may be due to the absence of methyl groups at 2-, 9-position of phenanthroline ligand in the cases of $\mathbf{C u - 1}$ and $\mathbf{C u - 4}$ which allows the complex to undergo structural distortion upon oxidation, whereas the steric hindrance offered by methyl groups on the diimine ligand of $\mathbf{C u}-2, \mathbf{C u}-3$ and $\mathbf{C u}-5$ inhibits such conformation change and may lead to ligand dissociation during oxidation.

\section{DFT calculations}

Density functional theory (DFT) and time-dependent DFT (TDDFT) calculations were performed to understand the electronic structures of Zn-1-Zn-3 and Cu-1-Cu-5 using Gaussian 09 package $^{\mathbf{1 6}}$ (for details, see the ESI $\dagger$ ). Fig. 6 depicts the optimized structure of $\mathbf{Z n - 1}$. The calculated $\mathrm{Zn} \cdots \mathrm{Zn}$ distances of 3.218$3.255 \AA$ and $\mathrm{Zn}-\mathrm{O}$ distances of $1.972-1.990 \AA$ are similar to related values reported for $\left[\mathrm{Zn}_{4} \mathrm{O}(\mathrm{AID})_{6}\right]$ ( $\mathrm{Zn}-\mathrm{O}$ 1.903-1.975 $\mathrm{A}$, $\mathrm{Zn} \cdots \mathrm{Zn}$ 3.147-3.209 А). ${ }^{9 \boldsymbol{b}}$ The emission data and the HOMO/ LUMO surfaces of Zn-1-Zn-3 are listed in Table 2 and Fig. 7. The emission of each complex originates from HOMO $\rightarrow$ LUMO (96\%) with oscillator strength of $0.3103,0.4513$ and 0.4377 , respectively. As shown in Fig. 7, each emission is intraligand charge transfer (ILCT) in nature because the HOMO and LUMO of each complex come from the same ligand. The calculated emission wavelength is 430, 441 and $448 \mathrm{~nm}$ for Zn-1, Zn-2 and Zn-3, respectively, which is in good agreement with corresponding experimental emission $\lambda_{\max }$ values.

Table 3 depicts the calculated structures of $\mathbf{C u - 1 - C u - 5 . ~ T h e ~}$ averaged bond distances of $\mathrm{Cu}-\mathrm{P}$ and $\mathrm{Cu}-\mathrm{N}$ are 2.33 and $2.13 \AA$, respectively, which are slightly longer than the corresponding experimental parameters of $\mathbf{C u - 1}$ and $\mathbf{C u}-\mathbf{3}$ (averaged $\mathrm{Cu}-\mathrm{P}=$ $2.25 \AA$ and $\mathrm{Cu}-\mathrm{N}=2.08 \AA$ ). The TDDFT calculated transition of $\mathrm{HOMO} \rightarrow$ LUMO for Cu-1-Cu-5 is at 469, 447, 458, 481 and 445 $\mathrm{nm}$, respectively, which is in good agreement with the corresponding experimental absorption $\lambda_{\max }$ values of 465, 438, 448, 473 and $434 \mathrm{~nm}$. The electronic transition is metal-to-ligand charge transfer (MLCT) in nature because the HOMO is mainly localized at the $\mathrm{Cu}$ atom and LUMO is mainly localized on the ligand.
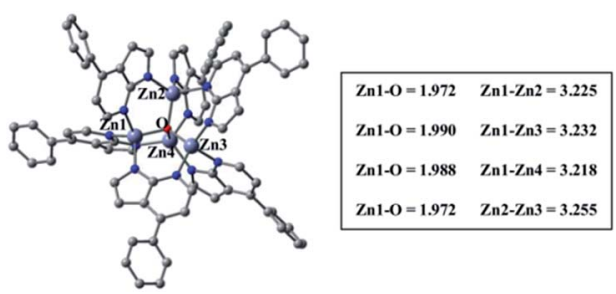

Fig. 6 Optimized ground-state $\left(\mathrm{S}_{0}\right)$ geometry of $\mathrm{Zn}-1$ by using PBEO/ 6-31G*(LANL2DZ).
Table 2 Emission data of Zn-1-Zn-3

\begin{tabular}{lllll}
\hline & \multicolumn{2}{l}{ Emission/nm } & & \\
\cline { 2 - 3 } & Calc. & Expt. & $\begin{array}{l}\text { Oscillator } \\
\text { strength }(f)\end{array}$ & Transition nature \\
\hline Zn-1 & 430 & 455 & 0.3103 & HOMO $\rightarrow$ LUMO (96\%) ILCT \\
Zn-2 & 441 & 466 & 0.4513 & HOMO $\rightarrow$ LUMO (96\%) ILCT \\
Zn-3 & 448 & 467 & 0.4377 & HOMO $\rightarrow$ LUMO (96\%) ILCT \\
\hline
\end{tabular}

As shown in Table 4, the calculated emission (fluorescence) $\lambda_{\text {max }}$ values of Cu-2 and Cu-3 are 599 and $611 \mathrm{~nm}$, respectively, which match very well with the experimental emission peaks of Cu-2 (592 nm) and Cu-3 (602 nm). The calculated energy gaps $\left(\Delta E\left(\mathrm{~S}_{1}-\mathrm{T}_{1}\right)\right)$ between singlet excited state $\left(\mathrm{S}_{1}\right)$ and triplet excited $\left(\mathrm{T}_{1}\right)$ are, respectively 1855 and $1129 \mathrm{~cm}^{-1}$ for $\mathbf{C u - 2}$ and $\mathbf{C u}-\mathbf{3}$, which are comparable to the $\Delta E\left(\mathrm{~S}_{1}-\mathrm{T}_{1}\right)=1300 \mathrm{~cm}^{-1}$ similarly calculated for $\mathrm{Cu}(\mathrm{POP})\left(\mathrm{pz}_{2} \mathrm{BH}_{2}\right)^{11 d}\left(\Delta E\left(\mathrm{~S}_{1}-\mathrm{T}_{1}\right)=1300 \mathrm{~cm}^{-1}\right)$ which displays a thermally activated delayed fluorescence (TADF) from the lowest excited singlet state $\left(S_{1}\right)$ at room temperature. The analysis of the emission decay lifetime versus temperature reveals the gap $\left(\Delta E\left(\mathrm{~S}_{1}-\mathrm{T}_{1}\right)\right)$ for $\mathbf{C u}-3$ to be $921 \mathrm{~cm}^{-1}$ (see Fig. 5) which is $208 \mathrm{~cm}^{-1}\left(\sim 0.6 \mathrm{kcal} \mathrm{mol}^{-1}\right)$ lower than the TDDFT calculated value $\left(1129 \mathrm{~cm}^{-1}\right)$. To test the validity of the calculated value, we did similar TDDFT calculation on the Cu(POP)-2 having a well-defined TADF property. ${ }^{11 e}$ The calculated emission of $\mathbf{C u}(\mathbf{P O P})-2$ is $561 \mathrm{~nm}$ at $\mathrm{S}_{1}$ excited state, which is in good agreement with the experimental emission data (555 nm); the calculated $\Delta E\left(\mathrm{~S}_{1}-\mathrm{T}_{1}\right)$ value is $1432 \mathrm{~cm}^{-1}$, which is $712 \mathrm{~cm}^{-1}\left(2.0 \mathrm{kcal} \mathrm{mol}^{-1}\right)$ larger than the experimental value of $720 \mathrm{~cm}^{-1} \cdot{ }^{11 e}$ For $\mathbf{C u}-2$ and $\mathbf{C u}-5$, the calculated $\Delta E\left(\mathrm{~S}_{1}-\mathrm{T}_{1}\right)$ value is 660 and $687 \mathrm{~cm}^{-1}$ larger than the experimental values, respectively. Since both the emissions of $S_{1}$ and $T_{1}$ were based on the optimized geometries in TDDFT calculation, the discrepancy between the experimental and calculated $\Delta E\left(\mathrm{~S}_{1}-\mathrm{T}_{1}\right)$ values might be due to the lack of the zero point energy correction of the excited states $\left(\mathrm{S}_{1} / \mathrm{T}_{1}\right)$. To obtain the zero point energy, one
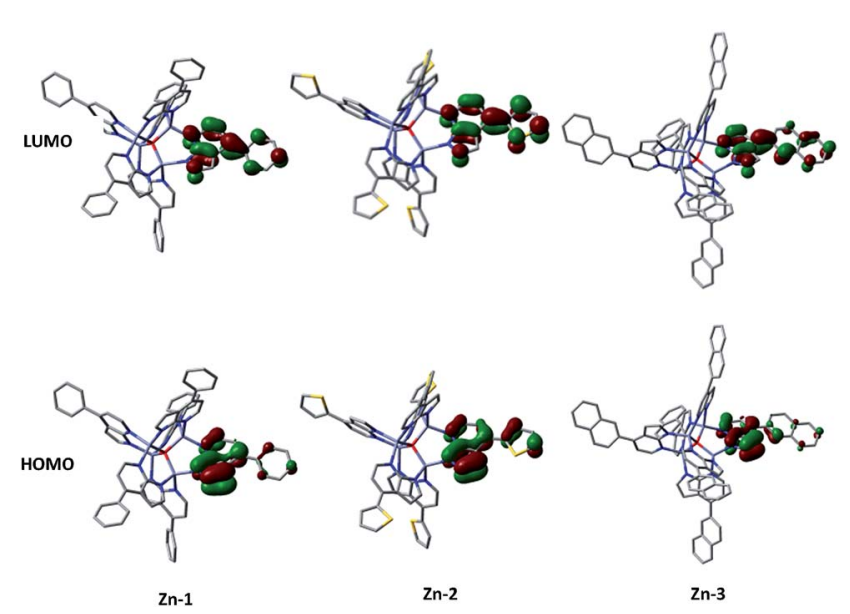

Fig. 7 Computed surfaces of HOMO and LUMO of Zn-1-Zn-3 (isovalue $=0.05$ ) 
Table 3 The calculated structural parameters $(\AA)$ of the copper( $($ ) complexes $(\mathrm{Cu}-1-\mathrm{Cu}-5)$ in ground state $\left(\mathrm{S}_{0}\right)$

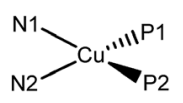

\begin{tabular}{lllll} 
& $\mathrm{Cu}-\mathrm{P} 1$ & $\mathrm{Cu}-\mathrm{P} 2$ & $\mathrm{Cu}-\mathrm{N} 1$ & $\mathrm{Cu}-\mathrm{N} 2$ \\
\hline $\mathrm{Cu}-1$ & 2.315 & 2.306 & 2.125 & 2.104 \\
$\mathrm{Cu}-2$ & 2.355 & 2.347 & 2.154 & 2.148 \\
$\mathrm{Cu}-3$ & 2.351 & 2.349 & 2.140 & 2.146 \\
$\mathrm{Cu}-4$ & 2.307 & 2.319 & 2.101 & 2.114 \\
$\mathrm{Cu}-5$ & 2.362 & 2.353 & 2.150 & 2.147 \\
\hline
\end{tabular}

needs to perform the frequency calculation in the excited state $\left(\mathrm{S}_{1} / \mathrm{T}_{1}\right)$, which is highly demanding in the context of computational resources and beyond the scope of this work.

It is informative to compare the calculated geometrical changes between the ground $\left(\mathrm{S}_{0}\right)$ and the excited states $\left(\mathrm{S}_{1} / \mathrm{T}_{1}\right)$ as depicted in Table 5. The P2-N2-N1-P1 dihedral angles of all the complexes in the ground state $\left(\mathrm{S}_{0}\right)$ are quite similar $\left(52.3^{-}\right.$ $52.8^{\circ}$ ). In excited states, however, the geometrical changes are quite different. For $\mathbf{C u}-\mathbf{1}$ and $\mathbf{C u}-\mathbf{4}$, the dihedral angle of P2-N2-N1-P1 changes dramatically in excited state $\left(\Delta\left(\mathrm{S}_{0}-\mathrm{S}_{1}\right)\right.$ $=20.2$ and 19.8; $\Delta\left(\mathrm{S}_{0}-\mathrm{T}_{1}\right)=12.8$ and 12.7). While for $\mathbf{C u}-2$, Cu-3 and $\mathbf{C u}-5$, their geometries are quite rigid in all states $\left(\Delta\left(\mathrm{S}_{0}-\mathrm{S}_{1}\right)=3.4,3.3\right.$ and $2.8 ; \Delta\left(\mathrm{S}_{0}-\mathrm{T}_{1}\right)=2.6,1.1$ and -0.2$)$. The smaller geometrical changes are related to smaller HuangRhys factor $\left(S_{\mathrm{M}}\right)$, which leads to smaller non-radiative decay constant and thus higher emission quantum yield. This is consistent with the experimental findings that, in the solid state at room temperature, $\mathbf{C u}-\mathbf{1}$ and $\mathbf{C u}-\mathbf{4}$ are weakly emissive with quantum yield of 0.01-0.018 while $\mathbf{C u - 2 , ~ C u - 3 ~ a n d ~} \mathbf{C u}-5$ are strongly emissive with quantum yield of $0.155-0.34$ (see Table 1 ).

The geometrical changes in excited state may also correlate to the emission energy. Cu-1 and Cu-2 were selected for comparison. Emissions of both $\mathbf{C u}-\mathbf{1}$ and $\mathbf{C u}-\mathbf{2}$ originate from HOMO $\rightarrow$ LUMO (over 97\%). The frontier molecular orbitals (FMOs) of $\mathbf{C u}-\mathbf{1}$ and $\mathbf{C u}-\mathbf{2}$ in the ground state and singlet excited state are shown in Fig. S62 and S63. $\dagger$ In the ground state $\left(\mathrm{S}_{0}\right)$, both $\mathbf{C u}-\mathbf{1}$ and $\mathbf{C u}-\mathbf{2}$ have similar HOMO-LUMO gap, which is in line with the similar UV-vis absorption spectra of the complexes. The excited states $\left(\mathrm{S}_{1}\right)$ of $\mathbf{C u}-\mathbf{1}$ and $\mathbf{C u}-\mathbf{2}$, because of their MLCT in nature, have the $\mathrm{Cu}$ atom in a formal $\mathrm{d}^{9}$ electronic configuration and then experience a noticeable JahnTeller effect, and the latter is the driving force for a more planar
Table 5 Comparison of the geometries in ground state $\left(S_{0}\right)$ and excited states $\left(\mathrm{S}_{1} / \mathrm{T}_{1}\right)$

\begin{tabular}{llll}
\hline & \multicolumn{3}{l}{ Dihedral angle $\mathrm{P} 2-\mathrm{N} 2-\mathrm{N} 1-\mathrm{P} 1{ }^{\circ}$} \\
\cline { 2 - 4 } & & & \\
\hline $\mathrm{N} 2$ & $\mathrm{~S}_{0}$ & $\mathrm{~S}_{1}$ & $\mathrm{~T}_{1}$ \\
\hline $\mathrm{Cu}-1$ & 52.8 & 32.6 & 40.0 \\
$\mathrm{Cu}-2$ & 52.4 & 49.0 & 49.8 \\
$\mathrm{Cu}-3$ & 52.3 & 49.0 & 51.2 \\
$\mathrm{Cu}-4$ & 52.4 & 32.6 & 39.7 \\
$\mathrm{Cu}-5$ & 52.3 & 49.5 & 52.5 \\
\hline
\end{tabular}

geometry in the excited state (smaller dihedral angle of P2-N2N1-P1, see Table 5). The more planar geometry (smaller dihedral angle of P2-N2-N1-P1) in the excited state leads to a higher energy level of HOMO (stronger $\sigma^{*}$ antibonding between metal and the ligand). For $\mathbf{C u}-\mathbf{1}$, its HOMO energy increases substantially due to the considerable geometrical distortion. As for $\mathbf{C u}-\mathbf{2}$, the steric effect of the methyl group confines the geometrical distortion thus the energy level of HOMO does not increase too much. Thus, Cu-2 has a higher energy emission than $\mathbf{C u}-1$ due to the smaller geometrical distortion in the excited state. This is also in line with the experimental findings described in previous sections.

In summary of this section, the low energy intense absorption bands of the $\mathrm{Cu}(\mathrm{I})$ complexes studied herein are metal to ligand charge transfer (MLCT) in nature. Geometrical distortion in the excited state is balanced by both the Jahn-Teller effect and steric effect of the substituent methyl group in the cases of complexes $\mathbf{C u}-\mathbf{2}, \mathbf{C u}-\mathbf{3}$ and $\mathbf{C u}-\mathbf{5}$. Such geometrical distortion not only affects the non-radiative decay constant but also the emission energy. TADF is possible for $\mathbf{C u}-\mathbf{2}, \mathbf{C u}-\mathbf{3}$ and $\mathbf{C u}-\mathbf{5}$ due to the small energy gap between first singlet and triplet excited state $\left(\Delta E\left(\mathrm{~S}_{1}-\mathrm{T}_{1}\right)\right) .^{11}$

\section{Electroluminescent properties of $\mathrm{Zn}-1-\mathrm{Zn}-3$}

Blue solution-processed OLEDs were fabricated with a simple architecture of ITO/PEDOT:PSS/PVK:OXD-7:Zn(II) complex/ $\mathrm{TmPyPb} / \mathrm{TPBi} / \mathrm{LiF} / \mathrm{Al}$. A mixture of PVK (polyvinylcarbazole) and OXD-7 [(1,3-bis[(4-tert-butylphenyl)-1,3,4-oxadiazolyl]phenylene)] with weight ratio of $90: 5$ was used as the host, TmPyPb $[1,3,5$-tri [(3-pyridyl)-phen-3-yl]benzene] as hole-blocking layer, and TPBi $\left[2,2^{\prime}, 2^{\prime \prime}-(1,3,5\right.$-benzinetriyl)tris(1-phenyl-1- $H$-benzimidazole $\left.)\right]$ as

Table 4 Emission data of $\mathrm{Cu}-1-\mathrm{Cu}-5$

\begin{tabular}{|c|c|c|c|c|}
\hline & $\mathrm{S}_{1}$ & $\mathrm{~T}_{1}$ & $\Delta E\left(\mathrm{~S}_{1}-\mathrm{T}_{1}\right)$ & $\operatorname{Expt}^{a}$ \\
\hline Cu-1 & $934 \mathrm{~nm}, \mathrm{H} \rightarrow \mathrm{L}(98.0 \%), f=0.03$ & 989 nm, H $\rightarrow$ L (96.4\%) & N.A. & Non-emissive \\
\hline $\mathrm{Cu}-2$ & $599 \mathrm{~nm}, \mathrm{H} \rightarrow \mathrm{L}(97.3 \%), f=0.10$ & $673 \mathrm{~nm}, \mathrm{H} \rightarrow \mathrm{L}(95.2 \%)$ & $1855 \mathrm{~cm}^{-1}$ & $592 \mathrm{~nm}$ \\
\hline $\mathrm{Cu}-4$ & $968 \mathrm{~nm}, \mathrm{H} \rightarrow \mathrm{L}(98.0 \%), f=0.03$ & $1031 \mathrm{~nm}, \mathrm{H} \rightarrow \mathrm{L}(96.5 \%)$ & N.A. & Non-emissive \\
\hline Cu-5 & $643 \mathrm{~nm}, \mathrm{H} \rightarrow \mathrm{L}(96.9 \%), f=0.05$ & $707 \mathrm{~nm}, \mathrm{H} \rightarrow \mathrm{L}(95.2 \%)$ & $1428 \mathrm{~cm}^{-1}$ & Non-emissive \\
\hline
\end{tabular}


electron-transporting layer. ${ }^{17}$ Fig. $8 \mathrm{a}-\mathrm{c}$ depict EL spectra of OLEDs fabricated with Zn-1-Zn-3 at dopant concentrations of 2$20 \mathrm{wt} \%$. Compared with photoluminescent (PL) spectra of thin film samples of Zn-1-Zn-3 depicted in Fig. S5 (ESI $\dagger$ ), EL spectra of corresponding devices at low dopant concentration of $2 \mathrm{wt} \%$ were slightly blue-shifted in energy. This could be explained by the overlapping of emissions originated from the PVK host and the $\mathrm{Zn}$ (II)-dopant due to incomplete energy transfer from PVK to $\mathrm{Zn}$ (II)-emitter at such low dopant concentration. ${ }^{\mathbf{8 g}, 17}$ Consequently, as depicted in Fig. 8d-f, EQEs of devices with 2 wt $\%$ $\mathrm{Zn}$ (II)-dopant were relatively low because of the low efficiency of PVK. ${ }^{8 g}$ Upon increasing the doping concentration of $\mathrm{Zn}$ (II)emitter to $8 \mathrm{wt} \%$, all EL spectra matched well to corresponding PL ones, suggesting efficient energy transfer from PVK to $\mathrm{Zn}$ (II)emitter. Thus, EQEs of all Zn-devices were improved in the cases of $8 \mathrm{wt} \%$ dopant concentration. Further increase in dopant concentration to $20 \mathrm{wt} \%$ led to a red shift in EL spectra of all devices; this could be the result of intermolecular interactions between the $\mathrm{Zn}$ (II) complexes. At such high dopant concentration, self-quenching of the $\mathrm{Zn}$ (II)-emitters became notable and therefore EQEs of all $\mathrm{Zn}$ (II)-OLEDs at $20 \mathrm{wt} \%$ dopant concentration were low. Among the blue OLEDs studied in this work, the one with $8 \mathrm{wt} \% \mathbf{Z n - 1}$ showed the highest EQE of $5.55 \%$ and $\mathrm{CE}$ of $8.12 \mathrm{~cd} \mathrm{~A}^{-1}$ (Table 6) attributed to the high emission quantum yield (0.96) of $\mathbf{Z n - 1}$ in the thin film (Table 1). These efficiency values are in general much higher than those of the devices fabricated with other blue luminescent $\mathrm{Zn}$ (II)
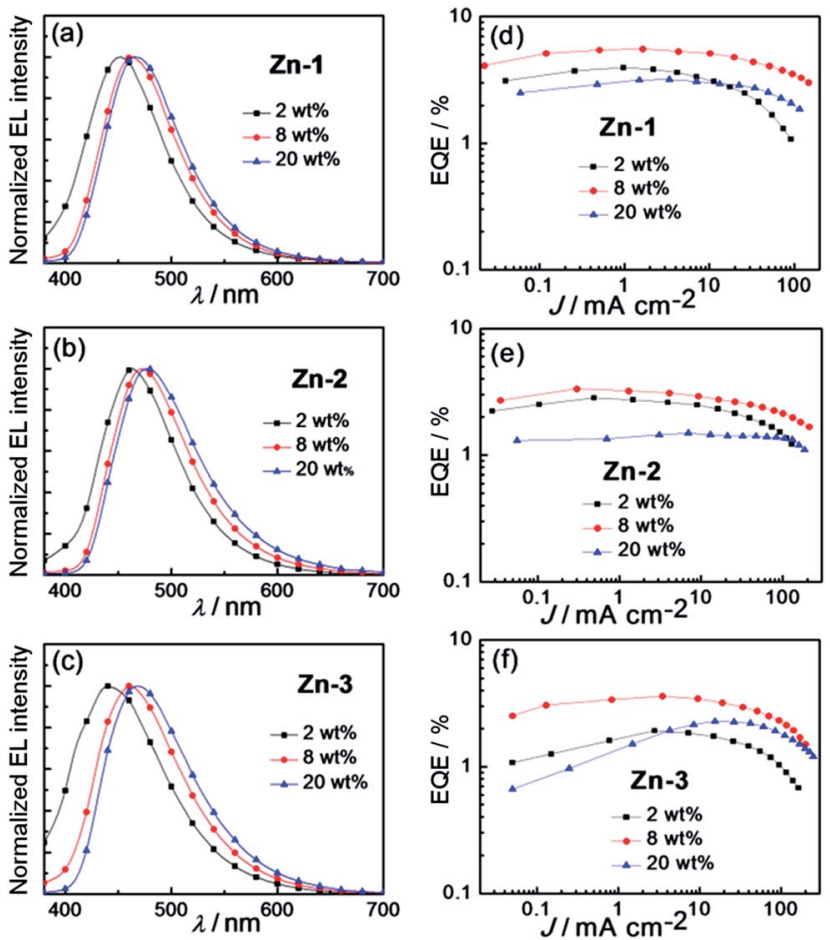

Fig. 8 Normalized EL spectra of solution-processed OLEDs based on (a) Zn-1, (b) Zn-2 and (c) Zn-3 at different doping concentration. EQEcurrent density characteristics of devices based on (d) Zn-1, (e) Zn-2 and (f) $\mathbf{Z n - 3}$ at different doping concentrations.

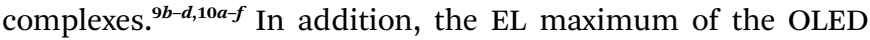
with $8 \mathrm{wt} \% \mathbf{Z n - 1}$ was located at $462 \mathrm{~nm}$ with CIE coordinates of (0.16, 0.19), suggesting $\mathbf{Z n - 1}$ could be a suitable blue emitter for white OLEDs.

\section{Electroluminescent properties of $\mathrm{Cu}-2, \mathrm{Cu}-3$ and $\mathrm{Cu}-5$}

Since Cu-1 and Cu-4 are non-emissive in solutions and weakly emissive in the solid state (Table 1), only EL properties of Cu-2, Cu-3 and Cu-5 were examined. Solution-processed OLEDs with architecture of ITO/PEDOT:PSS/PYD2:Cu(I) emitter/DPEPO/ TPBi/LiF/Al (PYD2/DPEPO device) were fabricated. In these devices, Cu-2, Cu-3 or Cu-5 was used as the emitter, PYD2 (2,6-dicarbazolo-1,5-pyridine) as the host, DPEPO [bis $\{2$ [di(phenyl)phosphino]phenyl\}ether oxide] as hole-blocking layer, and TPBi as electron-transporting layer. As depicted in Fig. 9 and Table 7, at low dopant concentration of $0.5 \mathrm{wt} \%$, relatively lower efficiency of $4.25,4.94$ and $2.83 \%$ were recorded in $\mathbf{C u}-2, \mathbf{C u}-\mathbf{3}$ and $\mathbf{C u}-\mathbf{5}$ devices due to incomplete energy transfer from PYD2 to $\mathrm{Cu}(\mathrm{I})$ complex at such low dopant concentration. Upon increasing the $\mathrm{Cu}(\mathrm{I})$ dopant concentration beyond $0.5 \mathrm{wt} \%$, energy transfer from PYD2 to these $\mathrm{Cu}(\mathrm{I})$ complexes became efficient and maximum EQEs of 16.57, 15.64 and $5.10 \%$, corresponding to CEs of $49.80,43.33$ and $14.75 \mathrm{~cd}$ $\mathrm{A}^{-1}$ have been achieved for the OLEDs with $5 \mathrm{wt} \% \mathbf{C u}-2,5 \mathrm{wt} \%$ Cu-3 and 2.5 wt\% Cu-5, respectively. The high EL efficiency of Cu-2 and Cu-3 devices is attributed to the emissions of $\mathbf{C u - 2}$ and Cu-3 to be TADF instead of prompt fluorescence. It is worthy to note that high EQE was achieved in the $\mathbf{C u}-\mathbf{2}$ device in spite of the incomplete energy transfer from the host DPY2 to $\mathbf{C u}-\mathbf{2}$ displayed in the PL spectrum of Cu-2 doped PYD thin film (Fig. S9a, ESI $\dagger$ ), suggesting that trapping mechanism plays an important role in the emission of the $\mathbf{C u - 2}$ device. For the $\mathbf{C u}-\mathbf{5}$ device, on the other hand, energy transfer can hardly take place from PYD2 to Cu-5 (Fig. S9b, ESI $\dagger$ ). This could be the main reason for the relatively low efficiency of the $\mathbf{C u - 5}$ device.

\section{White OLEDs with luminescent $\mathrm{Cu}$ (I) and $\mathrm{Zn}$ (II) complexes}

Since EL maxima of PYD2/DPEPO devices with Cu-2 and Cu-3, respectively, locate at 558 and $574 \mathrm{~nm}$ (see Fig. 9), Cu-3 is more suitable as a long-wavelength emitter used in the fabrication of white-light devices. Thus, solution-processed OLED with the architecture of ITO/PEDOT:PSS/PYD2:FIrpic (10 wt\%):Cu-3 (1 wt\%)/DPEPO/TPBi/LiF/Al was fabricated and characterized, in which bis[(4,6-difluorophenyl)pyridinato- $\left.N, C^{2}\right]$-(picolinato) iridium (FIrpic) ${ }^{5 c}$ and $\mathbf{C u}-3$ were used as blue and yellow dopants, respectively. Although high EQE of $16.77 \%$ and power efficiency of $22.19 \mathrm{~lm} \mathrm{~W}^{-1}$ have been achieved with this [Cu-3, FIrpic] device, its CIE coordinates of $(0.37,0.48)$ and colour rendering index (CRI) of 61 are not satisfactory for lighting application. Generally, colour quality of a white OLED can be improved by covering a larger visible spectral region with its EL spectrum. It was reported that EL of the $\mathrm{Cu}(\mathrm{I})$ complex $[\mathrm{Cu}(\mathrm{dnbp})(\mathrm{DEPhos})] \mathrm{BF}_{4}$ is strongly dependent on host and holeblocking layer (HBL) materials used in the corresponding OLED. ${ }^{13 c}$ Similarly, EL spectra of OLEDs with the architecture of ITO/PEDOT:PSS/PVK:OXD-7:Cu-3/3TPYMB/TPBi/LiF/Al (PVK/ 
Table 6 Key performance parameters of OLEDs with Zn-1-Zn-3

\begin{tabular}{|c|c|c|c|c|c|}
\hline Complex (wt\%) & $\mathrm{L}^{a} / \mathrm{cd} \mathrm{m}{ }^{-2}$ & $\mathrm{CE}^{b} / \mathrm{cd} \mathrm{A}^{-1}$ & $\mathrm{PE}^{c} / \mathrm{lm} \mathrm{W}^{-1}$ & $\operatorname{EQE}^{d}(\%)$ & $\operatorname{CIE}^{e}(x, y)$ \\
\hline Zn-1 (2\%) & 1080 & 4.29 & 2.31 & 3.94 & $(0.16,0.15)$ \\
\hline Zn-1 (8\%) & 6503 & 8.12 & 4.28 & 5.55 & $(0.16,0.19)$ \\
\hline Zn-2 (2\%) & 2290 & 4.14 & 2.37 & 2.83 & $(0.17,0.20)$ \\
\hline Zn-2 (8\%) & 6300 & 6.00 & 3.14 & 3.33 & $(0.18,0.26)$ \\
\hline Zn-2 (20\%) & 4095 & 3.00 & 1.50 & 1.49 & $(0.19,0.30)$ \\
\hline Zn-3 (20\%) & 5430 & 4.12 & 1.88 & 2.29 & $(0.18,0.25)$ \\
\hline
\end{tabular}

${ }^{a}$ Max. luminance. ${ }^{b}$ Max. current efficiency. ${ }^{c}$ Max. power efficiency. ${ }^{d}$ Max. external quantum efficiency. ${ }^{e}$ CIE coordinates at $100 \mathrm{~cd} \mathrm{~m}{ }^{-2}$.
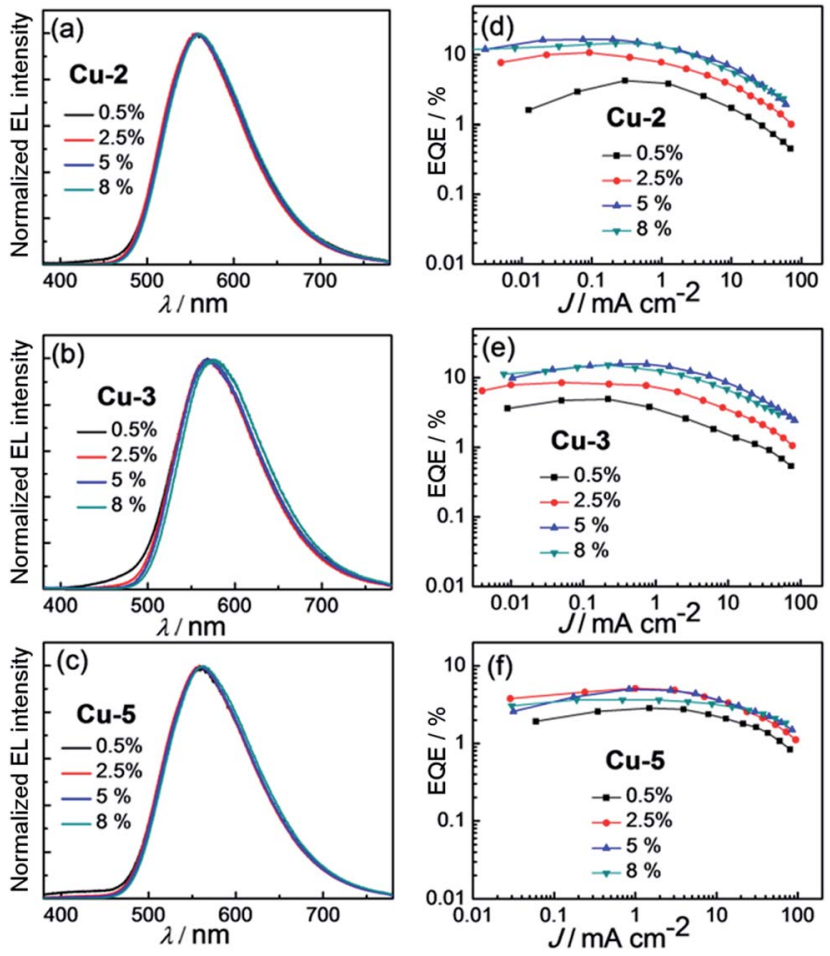

Fig. 9 Normalized EL spectra of PYD2/DPEOP devices based on (a) $\mathrm{Cu}-2$, (b) $\mathrm{Cu}-3$ and (c) $\mathrm{Cu}-5$ with different doping concentrations. EQE-current density characteristics of PYD2/DPEOP devices based on (d) $\mathrm{Cu}-2$, (e) $\mathrm{Cu}-3$ and (f) $\mathrm{Cu}-5$ at different doping concentrations.

3TPYMB devices) were shifted to lower energy compared with that of PYD2/DPEPO as depicted in Fig. S25 (ESI $\dagger$ ). By applying the PVK/3TPYMB device structure on the white OLED based on FIrpic and Cu-3, that is ITO/PEDOT:PSS/PVK:OXD-7:FIrpic (10 wt\%):Cu-3 (1 wt\%)/3TPYMB/TPBi/LiF/Al, emission of Cu-3 was red-shifted by $\sim 23 \mathrm{~nm}$ and therefore CRI of this white OLED was improved to 71 with CIE coordinates of $(0.37,0.45)$ as depicted in Fig. 10a. Since the EL efficiency of $\mathbf{C u - 3}$ was lower in the PVK/3TPYMB device structure (Table S1, ESI $\dagger$ ), the maximum efficiency (14.27\%) of the white OLED with PVK/ 3TPYMB structure was lower. For the same reason, emission ratio of $\mathbf{C u}-3$ /FIrpic was also lower in this device as depicted in Fig. 10a. The PVK/3TPYMB structure was also used to fabricate white solution-processable OLEDs with solely first-row transition-metal complexes. The white device was constructed as ITO/ PEDOT:PSS/PVK:OXD-7:Zn-1 (10 wt\%):Cu-3 (1 wt\%)/3TPYMB/ $\mathrm{TPBi} / \mathrm{LiF} / \mathrm{Al}$, in which $\mathbf{Z n - 1}$ and $\mathbf{C u - 3}$ were used as blue and orange light-emitting materials, respectively.

Fig. 10c depicts the dependence of EL spectra for the white OLED on the driving voltages; at low voltage of 7 V, orange Cu-3 emission dominated the EL spectrum, indicating energy transfer from Zn-1 to Cu-3. Upon increasing the driving voltage, Zn-1 emission increased and CIE coordinates were shifted from $(0.42,0.44)$ at $9 \mathrm{~V}$ to $(0.35,0.44)$ at $15 \mathrm{~V}$. Nevertheless, the corresponding CRI only slightly decreased from 81 to 76 while the luminance of this device increased from 300 to $3150 \mathrm{~cd} \mathrm{~m}^{-2}$ as listed in Table S2 (ESI $\dagger$ ). Power efficiency-EQE-current density characteristics of this OLED are depicted in Fig. 10d. Maximum $\mathrm{EQE}$ of $6.88 \%$, corresponding to $\mathrm{CE}$ of $14.67 \mathrm{~cd} \mathrm{~A}^{-1}$, and power efficiency of $6.58 \mathrm{~lm} \mathrm{~W}^{-1}$ have been achieved. To our best knowledge, these performance data are the best among those of the reported white solution-processed OLEDs with fluorescent emitters. ${ }^{4 a-c}$

Device stability of OLEDs with Zn-1 (8 wt\%), Cu-3 (5 wt\%), as well as that of the white OLED device with both Zn-1 (10 wt\%) and $\mathbf{C u}-3$ (1 wt\%), was investigated and the results are depicted in Fig. S27 (ESI $\dagger$ ). The initial luminance for all devices was 200 $\mathrm{cd} \mathrm{m}^{-2}$, and the half lifetimes $\left(T_{50}\right)$ were 18, 250 and $22 \mathrm{~min}$ for Zn-1, Cu-3, and white (Zn-1 + Cu-3) OLEDs, respectively. These device lifetimes are not good for practical applications and could partly be attributed to the instability of the PVK host. ${ }^{18}$ Nevertheless, the device lifetime of the Cu-3 device is comparable to the reported value of the OLED based on fac-tris(2phenylpyridine)iridium doped in PVK host. ${ }^{18 b}$

We conceived the possibility to develop blue and hence white solution-processed OLEDs with full $\mathrm{Cu}(\mathrm{I})$-emitters. For this reason, we prepared the literature reported $\mathrm{Cu}(\mathrm{pop})\left(\mathrm{pz}_{2} \mathrm{Bph}_{2}\right)$ which is a blue emitter with $\lambda_{\max }$ at $464 \mathrm{~nm}$ and high PL efficiency of $90 \% ;^{11 d}$ we used $\mathbf{C u}-3$ to be the orange emitter for the $\mathrm{Cu}$-based white OLED. To fabricate such device, both $\mathrm{Cu}(\mathrm{I})$ complexes should be co-doped in a common host material, such as PYD-2. A solution-processed OLED with the architecture of ITO/PEDOT:PSS/PYD2:Cu(pop) $\left(\mathrm{pz}_{2} \mathrm{Bph}_{2}\right)(10 \mathrm{wt} \%) / \mathrm{DPEPO} /$ $\mathrm{TPBi} / \mathrm{LiF} / \mathrm{Al}$ was therefore investigated in order to test EL of 
Table 7 Key parameters of PYD2/DPEOP OLEDs with Cu-2, Cu-3, and Cu-5

\begin{tabular}{|c|c|c|c|c|c|}
\hline Complex (wt\%) & $\mathrm{L}^{a} / \mathrm{cd} \mathrm{m}{ }^{-2}$ & $\mathrm{CE}^{b} / \mathrm{cd} \mathrm{A}^{-1}$ & $\mathrm{PE}^{c} / \mathrm{lm} \mathrm{W}^{-1}$ & $\mathrm{EQE}^{d}(\%)$ & $\operatorname{CIE}^{e}(x, y)$ \\
\hline Cu-2 (0.5\%) & 1000 & 13.33 & 7.62 & 4.25 & $(0.43,0.53)$ \\
\hline Cu-2 (2.5\%) & 2250 & 33.51 & 17.77 & 10.80 & $(0.44,0.53)$ \\
\hline Cu-2 (8\%) & 3840 & 43.83 & 20.16 & 14.63 & $(0.44,0.53)$ \\
\hline Cu-3 $(0.5 \%)$ & 1100 & 13.64 & 7.43 & 4.94 & $(0.45,0.50)$ \\
\hline Cu-3 (2.5\%) & 2280 & 23.60 & 12.57 & 8.47 & $(0.47,0.51)$ \\
\hline Cu-5 (0.5\%) & 1900 & 8.06 & 4.22 & 2.83 & $(0.43,0.52)$ \\
\hline Cu-5 $(2.5 \%)$ & 3030 & 14.75 & 7.73 & 5.10 & $(0.44,0.53)$ \\
\hline Cu-5 (5\%) & 3680 & 14.41 & 7.55 & 4.98 & $(0.44,0.53)$ \\
\hline Cu-5 (8\%) & 3740 & 10.53 & 6.01 & 3.64 & $(0.45,0.53)$ \\
\hline
\end{tabular}

${ }^{a}$ Max. luminance. ${ }^{b}$ Max. current efficiency. ${ }^{c}$ Max. power efficiency. ${ }^{d}$ Max. external quantum efficiency. ${ }^{e}$ CIE coordinates at $100 \mathrm{~cd} \mathrm{~m}^{-2}$.
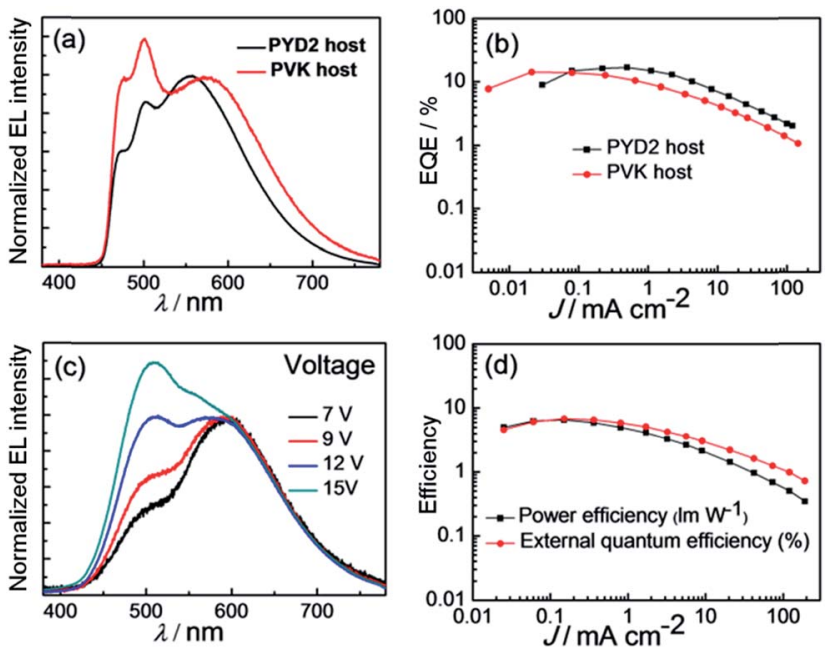

Fig. 10 (a) Normalized EL spectra and (b) EQE-power efficiencycurrent density characteristics of the white OLED with 10 wt\% FIrpic and 1 wt\% Cu-3 using PYD2/DPEPO or PVK/3TPYMB device structure. (c) EL spectra at different driving voltages and (d) EQE-power efficiency-current density characteristics of the white OLED with $10 \mathrm{wt} \%$ $\mathrm{Zn}-1$ and $1 \mathrm{wt} \% \mathrm{Cu}-3$

$\mathrm{Cu}(\mathrm{pop})\left(\mathrm{pz}_{2} \mathrm{Bph}_{2}\right)$ in PYD-2 host. As depicted in Fig. S26, $\dagger$ the emission colour of this device was green instead of blue and the EQE was $3.2 \%$. Thus the blue emission from $\mathrm{Cu}(\mathrm{pop})\left(\mathrm{pz}_{2} \mathrm{Bph}_{2}\right)$ can only be obtained in the powder state but not in thin doped film.

\section{General remarks}

Phosphorescent metal complexes, such as that of Ir(III) and $\mathrm{Pt}(\mathrm{II})$, have been extensively investigated and used as emitters in high efficiency OLEDs. ${ }^{1,2,19,20}$ Nevertheless, strongly luminescent metal complexes from inexpensive earth-abundant metals should be appealing especially for low-cost solution-processed OLEDs. Because of the earth abundance and eco-friendly nature of zinc metal, $\mathrm{Zn}$ (II) complexes are potentially useful lightemitting materials to realize production of low-price OLEDs in large scale. The photophysical and/or EL properties of several strongly blue luminescent Zn(II) complexes had been reported in our previous works. ${ }^{9 b, 21}$ The new Zn(II) complex Zn-1 in this work has a high emission quantum yield of 0.96 (see Table 1) in thin PMMA film and was observed to deliver the highest EL efficiency of $5.55 \%$ (see Table 6) among those of blue OLEDs with other Zn(II) complexes as light-emitting material. ${ }^{10}$

Recent works showed that $\mathrm{Cu}(\mathrm{I})$ complexes have the potential to be developed into efficient light-emitting materials for high performance OLEDs. ${ }^{12,13}$ Maximum EQEs of up to $21.3 \%$ and $15.0 \%$ for vacuum-deposited and solution-processed OLEDs, respectively, fabricated with luminescent $\mathrm{Cu}(\mathrm{I})$ complexes had been reported. ${ }^{12 b, 13 c}$ The first report ${ }^{22 a}$ on EL property of $\mathrm{Cu}(\mathrm{I})$ complexes appeared at almost the same time as that of Os(II) and Pt(II) complexes ${ }^{23}$ with the EL proposed to come from triplet excited state(s) (phosphorescence). ${ }^{22}$ Yersin and co-workers extensively developed the $\mathrm{Cu}(\mathrm{I})$ complexes which display TADF emission. ${ }^{11}$ Recently, Peters and co-workers demonstrated the DF mechanism to account for both PL and EL of the dinuclear $\mathrm{Cu}(\mathrm{I})$ complex supported by bis(phosphine)diarylamido ligand; this $\mathrm{Cu}(\mathrm{I})$ complex has a small $\mathrm{S}_{1}-\mathrm{T}_{1}$ energy gap. ${ }^{12 a}$ Adachi and co-workers reported the $\mathrm{Cu}(\mathrm{I})$ complexes [Cu(dnbp)(DPEPhos)] $\mathrm{BF}_{4}$ and $[\mathrm{Cu}(\mu \mathrm{I}) \mathrm{dppb}]_{2}$ to harvest both singlet and triplet excitons. $^{13 c}$ In the present work, PL of $\mathbf{C u}-2$ and $\mathbf{C u}-3$ has been studied by ns-TRE. Both the spectral evolution data and decay dynamics (see Fig. 4) from TRE experiments are compatible with the mechanism proposed by Yersin and co-workers in that the delayed fluorescence comes from thermal activated conversion from triplet states lying close in energy to the $S_{1}$ singlet excited state. Maximum EQEs of 16.57 and $15.64 \%$ have been achieved for the solution-processed OLEDs with $5 \mathrm{wt} \%$ Cu-2 and 5 wt\% Cu-3 as emitter, respectively. Such high EL efficiency of Cu-2- and Cu-3-devices is attributed to the emission of these two $\mathrm{Cu}(\mathrm{I})$ complexes to be TADF in nature.

In the EL studies of the blue and orange OLED devices, the roll-off of EQE at high luminance is the least pronounced for the devices with the highest dopant concentration, such as $20 \mathrm{wt} \%$ for $\mathrm{Zn}$ (II) complexes and $8 \%$ for $\mathrm{Cu}(\mathrm{I})$ complexes. Since EQE rolloff of OLED devices is mainly caused by exciton-polaron 
annihilation and field-induced quenching, ${ }^{24}$ the high dopant concentration in the EML, the less exciton formed in the host molecules would be quenched at high luminance. This is because energy transfer from host to dopant is faster and therefore lifetime of host excitons is shorter in the OLED with high dopant concentration. In addition, the relatively lower maximum EQE of the device with the highest dopant concentration caused by singlet-singlet and/or triplet-triplet annihilation also contributes to the least pronounced EQE roll-off.

By combining the blue emission of $\mathrm{Zn}$ (II) complexes and orange emission of $\mathrm{Cu}(\mathrm{I})$ complexes, solution-processed white OLEDs have been realized. Since the EL spectrum of the $\mathrm{Cu}(\mathrm{I})$ complex-device is affected by host and HBL materials, both CIE coordinates and CRI of the white OLED fabricated with longwavelength $\mathrm{Cu}(\mathrm{I})$ emitter can be tuned by varying both host and HBL materials. With the device structure of ITO/ PEDOT:PSS/PVK:OXD-7:Zn-1:Cu-/3TPYMB/TPBi/LiF/Al, a solution-processed white OLED with CIE coordinates of $(0.42,0.44)$ and $\mathrm{CRI}=81$ at $300 \mathrm{~cd} \mathrm{~m}^{-2}$ has been realized. The maximum EQE of $6.88 \%$ of this device is the highest among those of the reported solution-processed white OLEDs with fluorescent emitters. ${ }^{4 a-c}$ It is conceived that both CIE coordinates and CRI could be further improved by using Zn(II) complexes having higher energy emission.

\section{Conclusions}

A panel of new fluorescent Zn(II) complexes, Zn-1-Zn-3, with high emission quantum yields of up to 0.96 in thin film samples have been developed. Blue solution-processed OLEDs with EQE of up to $5.55 \%$ were accomplished with Zn-1. EL properties of the yellow to orange emitting $\mathrm{Cu}(\mathrm{I})$ complexes, $\mathbf{C u}-\mathbf{2}, \mathbf{C u}-\mathbf{3}$ and Cu-5, were studied. Both EL spectrum and efficiency of solutionprocessed OLED fabricated with $\mathbf{C u}-\mathbf{2}$ or $\mathbf{C u}-\mathbf{3}$ can be varied by changing the host and BHL materials of the corresponding device. With PYD2/DPEOP as host/BHL, maximum EQEs of $16.57 \%$ and $15.64 \%$ have been achieved for the devices fabricated with $\mathbf{C u}-\mathbf{2}$ and $\mathbf{C u}-\mathbf{3}$, respectively. By using $\mathbf{Z n - 1}$ as the blue emitter and $\mathbf{C u}-3$ as the orange one, a maximum EQE of $6.88 \%$ and good colour quality with CIE coordinates of $(0.42,0.44)$ and $\mathrm{CRI}=81$ at $300 \mathrm{~cd} \mathrm{~m}^{-2}$ were achieved.

\section{Acknowledgements}

We gratefully acknowledge the support from the Theme-Based Research Scheme (T23-713/11), the National Key Basic Research Program of China (no. 2013CB834802), the National Natural Science Foundation of China (no. 61274002), Strategic Research Theme of HKU on New Material and the Innovation and Technology Commission of the HKSAR Government (ITS/084/10). This work was also supported by Guangdong Special Project of the Introduction of Innovative R\&D Teams. We thank Dr KamHung Low for the collection of X-ray diffraction data and crystal structure determination of $\mathrm{Zn}_{4} \mathrm{O}(\mathrm{AID})_{6}$.

\section{Notes and references}

1 (a) J. H. Burroughes, D. D. C. Bradley, A. R. Brown, R. N. Marks, K. Mackay, R. H. Friend, P. L. Burns and A. B. Holmes, Nature, 1990, 347, 539; (b) B. Zhang, G. Tan, C.-S. Lam, B. Yao, C.-L. Ho, L. Liu, Z. Xie, W.-Y. Wong, J. Ding and L. Wang, Adv. Mater., 2012, 24, 1873; (c) C. Cebrián, M. Mauro, D. Kourkoulos, P. Mercandelli, D. Hertel, K. Meerholz, C. A. Strassert and L. De Cola, Adv. Mater., 2013, 25, 437.

2 (a) T. Earmme, E. Ahmed and S. A. Jenekhe, Adv. Mater., 2010, 22, 4744; (b) G. Liaptsis and K. Meerholz, Adv. Funct. Mater., 2013, 23, 359; (c) C.-L. Ho and W.-Y. Wong, New J. Chem., 2013, 37, 1665.

3 (a) X. Gong, W. Ma, J. C. Ostrowski, G. C. Bazan, D. Moses and A. J. Heeger, Adv. Mater., 2004, 16, 615; (b) H. Wu, L. Ying, W. Yang and Y. Cao, Chem. Soc. Rev., 2009, 38, 3391; (c) G. Zhou, W.-Y. Wong and S. Suo, J. Photochem. Photobiol., C, 2010, 11, 133; (d) L. Ying, C.-L. Ho, H. Wu, Y. Cao and W.-Y. Wong, Adv. Mater., 2014, 26, 2459.

4 (a) P.-I. Shih, C.-F. Shu, Y.-L. Tung and Y. Chi, Appl. Phys. Lett., 2006, 88, 251110; (b) H. A. Al Attar, A. P. Monkman, M. Tavasli, S. Bettington and M. R. Bryce, Appl. Phys. Lett., 2005, 86, 121101; (c) J. Jiang, Y. Xu, W. Yang, R. Guan, Z. Liu, H. Zhen and Y. Cao, Adv. Mater., 2006, 18, 1769; (d) Y. Sun, N. C. Giebink, H. Kanno, B. Ma, M. E. Thompson and S. R. Forrest, Nature, 2006, 440, 908; (e) G. Schwartz, M. Pfeiffer, S. Reineke, K. Walzer and K. Leo, Adv. Mater., 2007， 19，3672; (f) C.-L. Ho, L.-C. Chi, W.-Y. Hung, W.-J. Chen, Y.-C. Lin, H. Wu, E. Mondal, G.-J. Zhou, K.-T. Wong and W.-Y. Wong, J. Mater. Chem., 2012, 22, 215. 5 (a) S.-W. Lai and C.-M. Che, in Transition Metal and Rare Earth Compounds, ed. H. Yersin, Springer, Berlin/ Heidelberg, vol. 241, 2004, pp. 27-63; (b) P. I. Djurovich and M. E. Thompson, in Highly Efficient OLEDs with Phosphorescent Materials, ed. H. Yersin, Wiley-VCH, Weinheim, 2008, pp. 131-161; (c) C. Adachi, R. C. Kwong, P. Djurovich, V. Adamovich, M. A. Baldo, M. E. Thompson and S. R. Forrest, Appl. Phys. Lett., 2001, 79, 2082; (d) H. Yersin, A. F. Rausch, R. Czerwieniec, T. Hofbeck and T. Fisher, Coord. Chem. Rev., 2011, 255, 2622; (e) P.-T. Chou, Y. Chi, M.-W. Chung and C.-C. Lin, Coord. Chem. Rev., 2011, 255, 2653; (f) L. Xiao, Z. Chen, B. Qu, J. Luo, S. Kong, Q. Gong and J. Kido, Adv. Mater., 2011, 23, 926; (g) H. Xu, R. Chen, Q. Sun, W. Lai, Q. Su, W. Huang and X. Liu, Chem. Soc. Rev., 2014, 43, 3259.

6 (a) S. Lamansky, P. Djurovich, D. Murphy, F. Abdel-Razzaq, H.-E. Lee, C. Adachi, P. E. Burrows, S. R. Forrest and M. E. Thompson, J. Am. Chem. Soc., 2001, 123, 4304; (b) G. Zhou, W.-Y. Wong, B. Yao, Z. Xie and L. Wang, Angew. Chem., Int. Ed., 2007, 46, 1149; (c) S. Reineke, T. C. Rosenow, B. Lüssem and K. Leo, Adv. Mater., 2010, 22, 3189; (d) S. O. Jeon, S. E. Jang, H. S. Son and J. Y. Lee, Adv. Mater., 2011, 23, 1436; (e) S.-Y. Kim, W.-I. Jeong, C. Mayr, Y.-S. Park, K.-H. Kim, J.-H. Lee, C.-K. Moon, W. Brütting and J.-J. Kim, Adv. Funct. Mater., 2013, 23, 
3896; $(f)$ H. Sasabe, H. Nakanishi, Y. Watanabe, S. Yano, M. Hirasawa, Y.-J. Pu and J. Kido, Adv. Funct. Mater., 2013, 23, 5550 .

7 (a) E. Rossi, A. Colombo, C. Dragonetti, D. Roberto, R. Ugo, A. Valore, L. Falciola, P. Brulatti, M. Cocchi and J. A. G. Williams, J. Mater. Chem., 2012, 22, 10650; (b) X.-C. Hang, T. Fleetham, E. Turner, J. Brooks and J. Li, Angew. Chem., Int. Ed., 2013, 52, 6753; (c) S. C. F. Kui, P. K. Chow, G. S. M. Tong, S.-L. Lai, G. Gheng, C.-C. Kwok, K.-H. Lo, M. Y. Ko and C.-M. Che, Chem.-Eur. J., 2013, 19, 69; (d) S. C. F. Kui, P.-K. Chow, G. Cheng, C.-C. Kwok, C. L. Kwong, K.-H. Low and C.-M. Che, Chem. Commun., 2013, 49, 1497; (e) G. Cheng, P.-K. Chow, S. C. F. Kui, C.-C. Kwok and C.-M. Che, Adv. Mater., 2013, 25, 6765; $(f)$ S.-L. Lai, W.-Y. Tong, S. C. F. Kui, M.-Y. Chan, C.-C. Kwok and C.-M. Che, Adv. Funct. Mater., 2013, 23, 5168; $(g)$ K. Li, G. Cheng, C. Ma, X. Guan, W.-M. Kwok, Y. Chen, W. Lu and C.-M. Che, Chem. Sci., 2013, 4, 2630; (h) X. Wang, S.-L. Gong, D. Song, Z.-H. Lu and S. Wang, Adv. Funct. Mater., 2014, 24, 7257; ( $i$ ) T. Fleetham, G. Li, L. Wen and J. Li, Adv. Mater., 2014, 26, 7116; (j) G. Cheng, S. C. F. Kui, W.-H. Ang, M.-Y. Ko, P.-K. Chow, C.-L. Kwong, C.-C. Kwok, C. Ma, X. Guan, K.-H. Low, S.-J. Su and C.-M. Che, Chem. Sci., 2014, 5, 4819; (k) P.-K. Chow, G. Cheng, G. S. M. Tong, W.-P. To, W.-L. Kwong, K.-H. Low, C.-C. Kwok, C. Ma and C.-M. Che, Angew. Chem., Int. Ed., 2015, 54, 2084.

8 (a) V. W.-W. Yam, K. M.-C. Wong, L.-L. Hung and N. Zhu, Angew. Chem., Int. Ed., 2005, 44, 3107; (b) K. M.-C. Wong, L.-L. Hung, W. H. Lam, N. Zhu and V. W.-W. Yam, J. Am. Chem. Soc., 2007, 129, 4350; (c) W.-P. To, G. S.-M. Tong, W. Lu, C. Ma, J. Liu, A. L.-F. Chow and C.-M. Che, Angew. Chem., Int. Ed., 2012, 51, 2654; (d) M.-C. Tang, D. P.-K. Tsang, M. M.-Y. Chan, K. M.-C. Wong and V. W.-W. Yam, Angew. Chem., Int. Ed., 2013, 52, 446; (e) W.-P. To, K. T. Chan, G. S. M. Tong, C. Ma, W.-M. Kwok, X. Guan, K.-H. Low and C.-M. Che, Angew. Chem., Int. Ed., 2013, 52, 6648; $(f)$ G. Cheng, K. T. Chan, W.-P. To and C.-M. Che, Adv. Mater., 2014, 26, 2540; (g) M.-C. Tang, D. P. K. Tsang, Y.-C. Wong, M.-Y. Chan, K. M. C. Wong and V. W. W. Yam, J. Am. Chem. Soc., 2014, 136, 17861.

9 (a) H. Kunkely and A. Vogler, J. Chem. Soc., Chem. Commun., 1990, 1204; (b) C.-F. Lee, K.-F. Chin, S.-M. Peng and C.-M. Che, J. Chem. Soc., Dalton Trans., 1993, 467; (c) H.-J. Son, W.-S. Han, J.-Y. Chun, B.-K. Kang, S.-N. Kwon, J. Ko, S. J. Han, C. Lee, S. J. Kim and S. O. Kang, Inorg. Chem., 2008, 47, 5666; (d) H. Xu, Z.-F. Xu, Z.-Y. Yue, P.-F. Yan, B. Wang, L.-W. Jia, G.-M. Li, W.-B. Sun and J.-W. Zhang, J. Phys. Chem. C, 2008, 112, 15517.

10 (a) G. Yu, S. Yin, Y. Liu, Z. Shuai and D. Zhu, J. Am. Chem. Soc., 2003, 125, 14816; (b) X. Xu, Y. Liao, G. Yu, H. You, C. Di, Z. Su, D. Ma, Q. Wang, S. Li, S. Wang, J. Ye and Y. Liu, Chem. Mater., 2007, 19, 1740; (c) S. P. Singh, Y. N. Mohapatra, M. Qureshi and S. S. Manoharan, Appl. Phys. Lett., 2005, 86, 113505; (d) Y. Hao, W. Meng, H. Xu, H. Wang, X. Liu and B. Xu, Org. Electron., 2011, 12, 136; (e) R. Wang, L. Deng, M. Fu, J. Cheng and J. Li, J. Mater. Chem., 2012, 22, 23454; (f) S.-G. Roh, Y.-H. Kim, K. D. Seo,
D. H. Lee, H. K. Kim, Y.-I. Park, J.-W. Park and J.-H. Lee, Adv. Funct. Mater., 2009, 19, 1663; (g) Z. Li, A. Dellali, J. Malik, M. Motevalli, R. M. Nix, T. Olukoya, Y. Peng, H. Ye, W. P. Gillin, I. Hernández and P. B. Wyatt, Inorg. Chem., 2013, 52, 1379; (h) Y. Sakai, Y. Sagara, H. Nomura, N. Nakamura, Y. Suzuki, H. Miyazaki and C. Adachi, Chem Commun., 2015, 51, 3181.

11 (a) H. Yersin, R. Czerwieniec and A. Hupfer, Proc. SPIE, 2012, 8435, 843508; (b) H. Yersin, R. Czerwieniec and U. Monkowius, WO Pat., 010650 A1, 2012; (c) H. Yersin, A. F. Rausch, R. Czerwieniec, T. Hofbeck and T. Fischer, Coord. Chem. Rev., 2011, 255, 2622; (d) R. Czerwieniec, J. $\mathrm{Yu}$ and $\mathrm{H}$. Yersin, Inorg. Chem., 2011, 50, 8293; (e) C. L. Linfoot, M. J. Leitl, P. Richardson, A. F. Rausch, O. Chepelin, F. J. White, H. Yersin and N. Robertson, Inorg. Chem., 2014, 53, 10854; ( $f$ ) M. J. Leitl, V. A. Krylova, P. I. Djurovich, M. E. Thompson and H. Yersin, J. Am. Chem. Soc., 2014, 136, 16032.

12 (a) J. C. Deaton, S. C. Switalski, D. Y. Kondakov, R. H. Young, T. D. Pawlik, D. J. Giesen, S. B. Harkins, A. J. M. Miller, S. F. Mickenberg and J. C. Peters, J. Am. Chem. Soc., 2010, 132, 9499; (b) M. Hashimoto, S. Igawa, M. Yashima, I. Kawata, M. Hoshino and M. Osawa, J. Am. Chem. Soc., 2011, 133, 10348; (c) K. J. Lotito and J. C. Peters, Chem. Commun., 2010, 46, 3690.

13 (a) Q. Zhang, Q. Zhou, Y. Cheng, L. Wang, D. Ma, X. Jing and F. Wang, Adv. Mater., 2004, 16, 432; (b) Q. Zhang, J. Ding, Y. Cheng, L. Wang, Z. Xie, X. Jing and F. Wang, Adv. Funct. Mater., 2007, 17, 2983; (c) Q. Zhang, T. Komino, S. Huang, S. Matsunami, K. Goushi and C. Adachi, Adv. Funct. Mater., 2012, 22, 2327.

14 B. Wang, D. P. Shelar, X.-Z. Han, T.-T. Li, X. Guan, W. Lu, K. Liu, Y. Chen, W.-F. Fu and C.-M. Che, Chem.-Eur. J., 2015, 21, 1184.

15 (a) M. Iwamura, S. Takeuchi and T. Tahara, J. Am. Chem. Soc., 2007, 129, 5248; (b) M. Iwamura, H. Watanabe, K. Ishii, S. Takeuchi and T. Tahara, J. Am. Chem. Soc., 2011, 133, 7728. 16 M. J. Frisch, G. W. Trucks, H. B. Schlegel, G. E. Scuseria, M. A. Robb, J. R. Cheeseman, G. Scalmani, V. Barone, B. Mennucci, G. A. Petersson, H. Nakatsuji, M. Caricato, X. Li, H. P. Hratchian, A. F. Izmaylov, J. Bloino, G. Zheng, J. L. Sonnenberg, M. Hada, M. Ehara, K. Toyota, R. Fukuda, J. Hasegawa, M. Ishida, T. Nakajima, Y. Honda, O. Kitao, H. Nakai, T. Vreven, J. A. Montgomery, J. E. Peralta, F. Ogliaro, M. Bearpark, J. J. Heyd, E. Brothers, K. N. Kudin, V. N. Staroverov, R. Kobayashi, J. Normand, K. Raghavachari, A. Rendell, J. C. Burant, S. S. Iyengar, J. Tomasi, M. Cossi, N. Rega, J. M. Millam, M. Klene, J. E. Knox, J. B. Cross, V. Bakken, C. Adamo, J. Jaramillo, R. Gomperts, R. E. Stratmann, O. Yazyev, A. J. Austin, R. Cammi, C. Pomelli, J. W. Ochterski, R. L. Martin, K. Morokuma, V. G. Zakrzewski, G. A. Voth, P. Salvador, J. J. Dannenberg, S. Dapprich, A. D. Daniels, O. Farkas, J. B. Foresman, J. V. Ortiz, J. Cioslowski and D. J. Fox, Gaussian 09, revision D.01, Gaussian, Inc., Wallingford, CT, 2013. 
17 G. Cheng, P.-K. Chow, S. C. F. Kui, C.-C. Kwok and C.-M. Che, Adv. Mater., 2013, 25, 6765.

18 (a) S.-C. Chang, G. He, F.-C. Chen, T-F. Guo and Y. Yang, Appl. Phys. Lett., 2001, 79, 2088; (b) T. Xiao, M. Cai, Y. Chen, R. Shinar and J. Shinar, Proc. SPIE, 2009, 7415, 741521.

19 (a) S. Reineke, T. C. Rosenow, B. Lüssem and K. Leo, Adv. Mater., 2010, 22, 3189; (b) Y. Tao, Q. Wang, C. Yang, C. Zhong, J. Qin and D. Ma, Adv. Funct. Mater., 2010, 20, 2923; (c) D. Tanaka, H. Sasabe, Y.-J. Li, S.-J. Su, T. Takeda and J. Kido, Jpn. J. Appl. Phys., 2007, 46, L10; (d) H. Sasabe, H. Nakanishi, Y. Watanabe, S. Yano, M. Hirasawa, Y.-J. Pu and J. Kido, Adv. Funct. Mater., 2013, 23, 5550.

20 (a) S. C. F. Kui, P. K. Chow, G. S. M. Tong, S.-L. Lai, G. Cheng, C.-C. Kwok, K.-H. Low, M. Y. Ko and C.-M. Che, Chem.-Eur. J., 2013, 19, 69; (b) S. C. F. Kui, P. K. Chow, G. Cheng, C.-C. Kwok, C. L. Kwong, K.-H. Low and C.-M. Che, Chem. Commun., 2013, 49, 1497; (c) G. Cheng, S. C. F. Kui, W.-H. Ang, M.-Y. Ko, P.-K. Chow, C.-L. Kwong, C.-C. Kwok, C. Ma, X. Guan, K.-H. Low, S.-J. Su and C.-M. Che, Chem. Sci., 2014, 5, 4819.

21 (a) K.-Y. Ho, W.-Y. Yu, K.-K. Cheung and C.-M. Che, Chem. Commun., 1998, 2101; (b) K.-Y. Ho, W.-Y. Yu, K.-K. Cheung and C.-M. Che, J. Chem. Soc., Dalton Trans., 1999, 1581; (c) C.-M. Che, C.-W. Wan, K.-Y. Ho and Z.-Y. Zhou, New J.
Chem., 2001, 25, 63; (d) J. Zhang, S. Gao and C.-M. Che, Eur. J. Inorg. Chem., 2004, 956.

22 (a) Y.-G. Ma, W.-H. Chan, X.-M. Zhou and C.-M. Che, New J. Chem., 1999, 23, 263; (b) M. Noto, Y. Goto and M. Era, Chem. Lett., 2003, 32, 32; (c) Q. Zhang, Q. Zhou, Y. Cheng, L. Wang, D. Ma, X. Jing and F. Wang, Adv. Mater., 2004, 16, 432; (d) D. G. Cuttell, S.-M. Kuang, P. E. Fanwick, D. R. McMillin and R. A. Walton, J. Am. Chem. Soc., 2002, 124, 6; (e) S.-M. Kuang, D. G. Cuttell, D. R. McMillin, P. E. Fanwick and R. A. Walton, Inorg. Chem., 2002, 41, 3313.

23 (a) Y. Ma, H. Zhang, J. Shen and C.-M. Che, Synth. Met., 1998, 94, 245; (b) M. A. Baldo, D. F. O'Brien, Y. You, A. Shoustikov, S. Sibley, M. E. Thompson and S. R. Forrest, Nature, 1998, 395, 151.

24 (a) H. Bouchriha, G. Delacote, P. Delannoy and M. Schott, J. Phys., 1974, 35, 577; (b) E. J. W. List, C.-H. Kim, A. K. Naik, U. Scherf, G. Leising, W. Graupner and J. Shinar, Phys. Rev. B: Condens. Matter, 2001, 64, 155204; (c) W. Stampor, J. Kalinowski, P. Di Marco and V. Fattori, Appl. Phys. Lett., 1997, 70, 1935; (d) J. Kalinowski, W. Stampor, J. Szmytkowski, D. Virgili, M. Cocchi, V. Fattori and C. Sabatini, Phys. Rev. B: Condens. Matter Mater. Phys., 2006, 74, 085316; (e) C. Murawski, K. Leo and M. C. Gather, Adv. Mater., 2013, 25, 6801. 